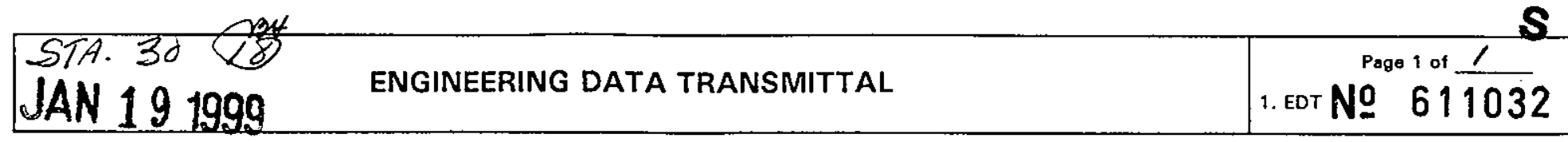

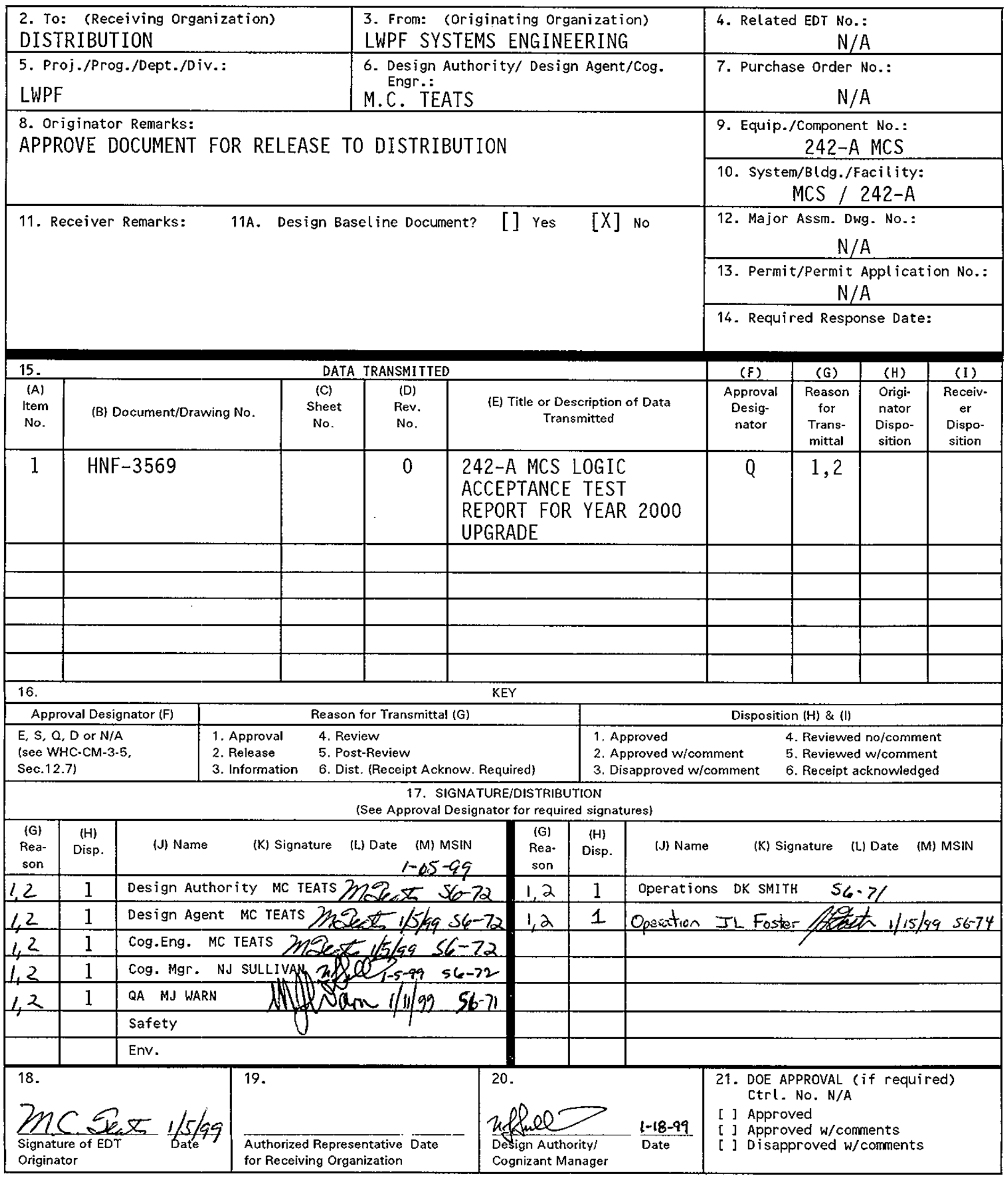

BD-7400-172-2 (05/96) GEF097 


\section{2-A MCS LOGIC ACCEPTANCE TEST REPORT FOR YEAR 2000 UPGRADE}

\section{M.C. TEATS}

WASTE MANAGEMENT HANFORD, Richland, WA 99352

U.S. Department of Energy Contract DE-AC06-96RL13200

EDT/ECN: 611032

Org Code: 32230

B\&R Code: EW3120071

UC: 2030

Charge Code: 101624 / AJ10

Total Pages: 122

Key Words: Distributive Control System, 242-A, MCS, Year 2000

Abstract: This report documents the acceptance test results for the 242-A Evaporator distributive control system upgrade to D/3 version $9.0-$ 2 for year 2000 compliance. Testing was performed per test procedure HNF-3568. There were no unresolved exceptions. The system responded correctly to all testing and meets the requirements to operate the 242-A Evaporator facility.

TRADEMARK DISCLAIMER. Reference herein to any specific commercial product, process, or service by trade name, trademark, manufacturer, or otherwise, does not necessarily constitute or imply its endorsement, recommendation, or favoring by the United States Government or any agency thereof or its contractors or subcontractors.

Printed in the United States of America. To obtain copies of this document, contact: Document Control Services, P.0. Box 950, Mailstop H6-08, Richland WA 99352, Phone (509). 372-2420;

Fax (509) 376-4989.
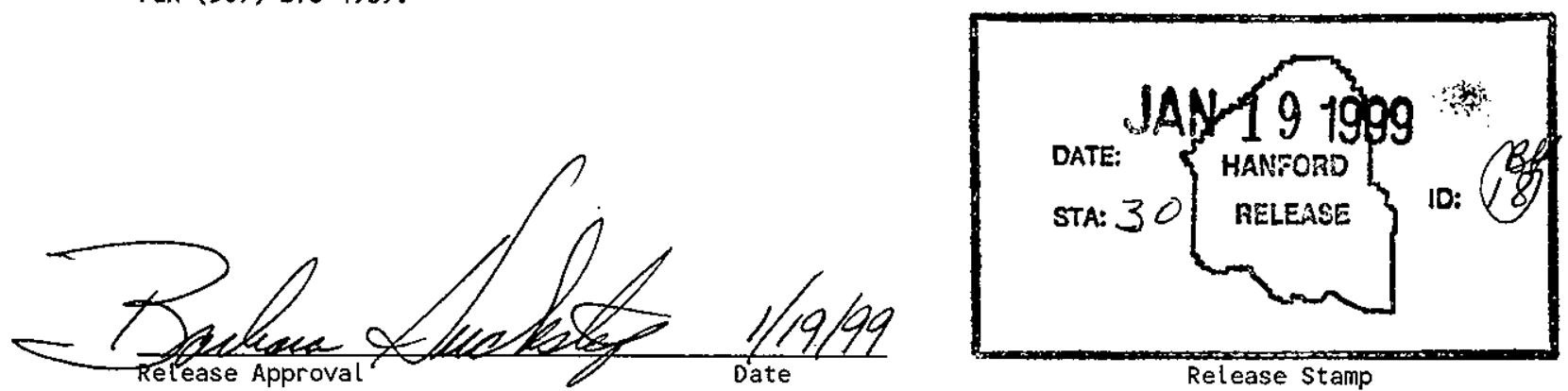

Approved for Public Release 
HNF-3569 REV 0

242-A MCS LOGIC

ACCEPTANCE TEST REPORT

FOR YEAR 2000 UPGRADE 


\section{TABLE OF CONTENTS}

2.0 TEST PLAN

3.0 TEST PROCEDURE

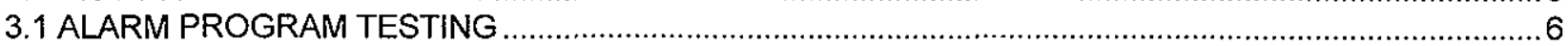

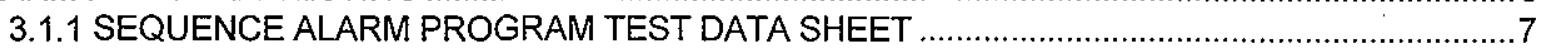

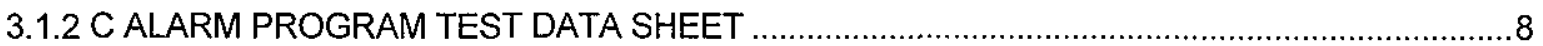

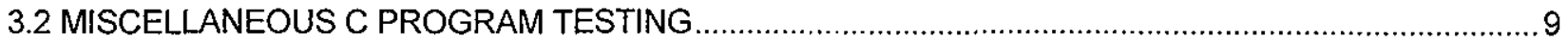

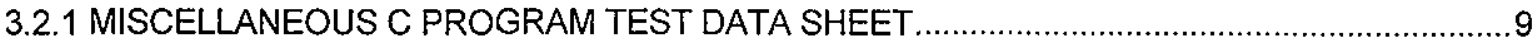

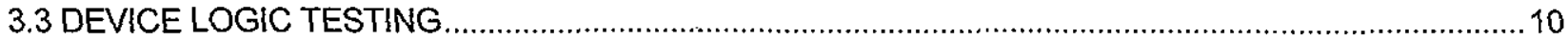

3.3.1 PCMO DEVICE DESCRIPTIONS AND DATA SHEETS .................................................11

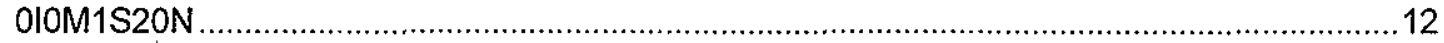

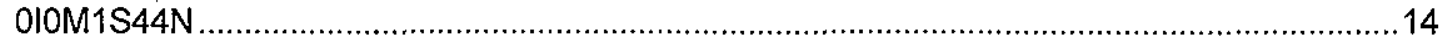

OIOM1S60N

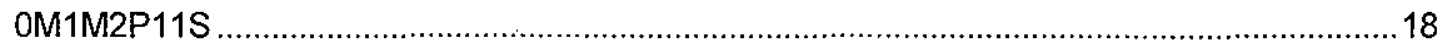

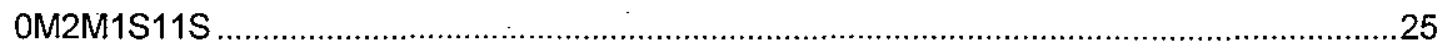

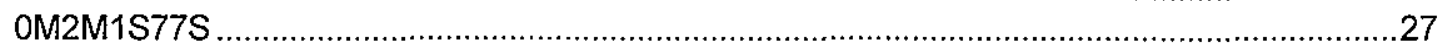

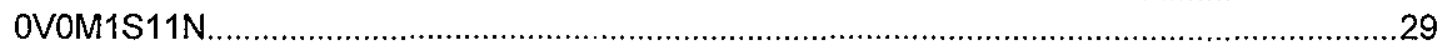

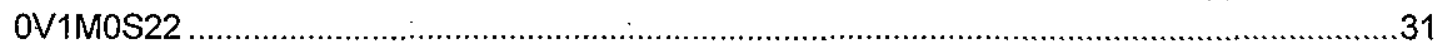

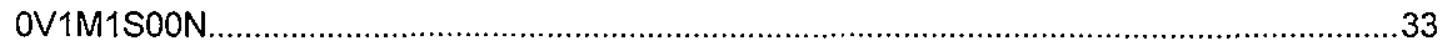

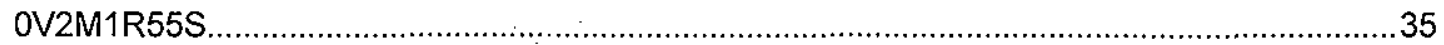

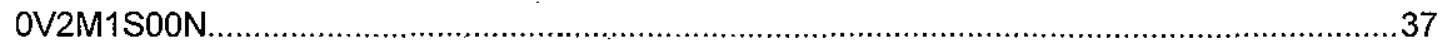

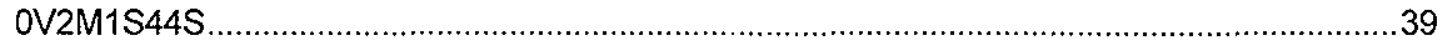

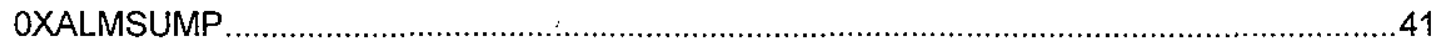

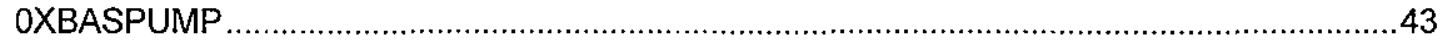

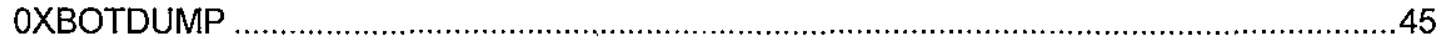

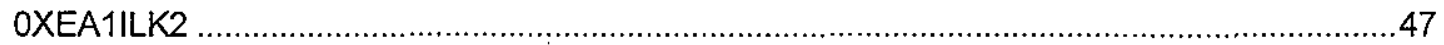

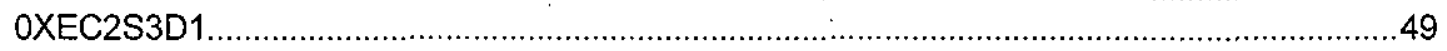

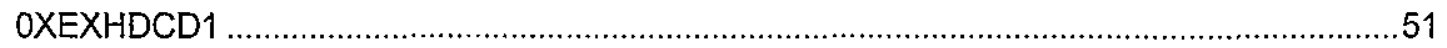

OXEXC1ILK

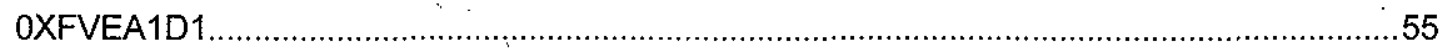

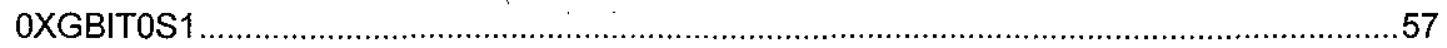

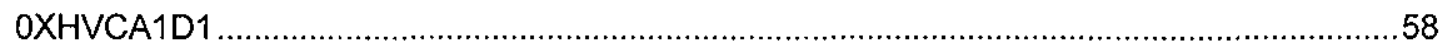

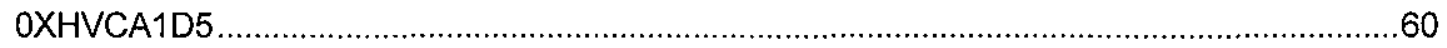

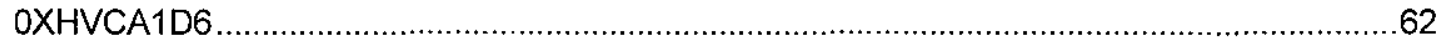

OXJGVALVE

OXMDPC100

OXMDPC106

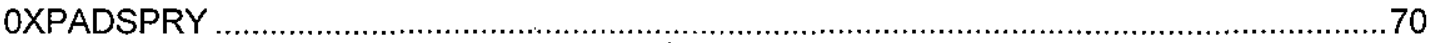

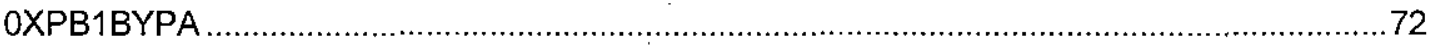

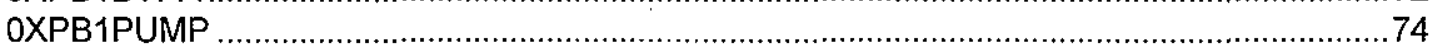


HNF-3569 REV 0

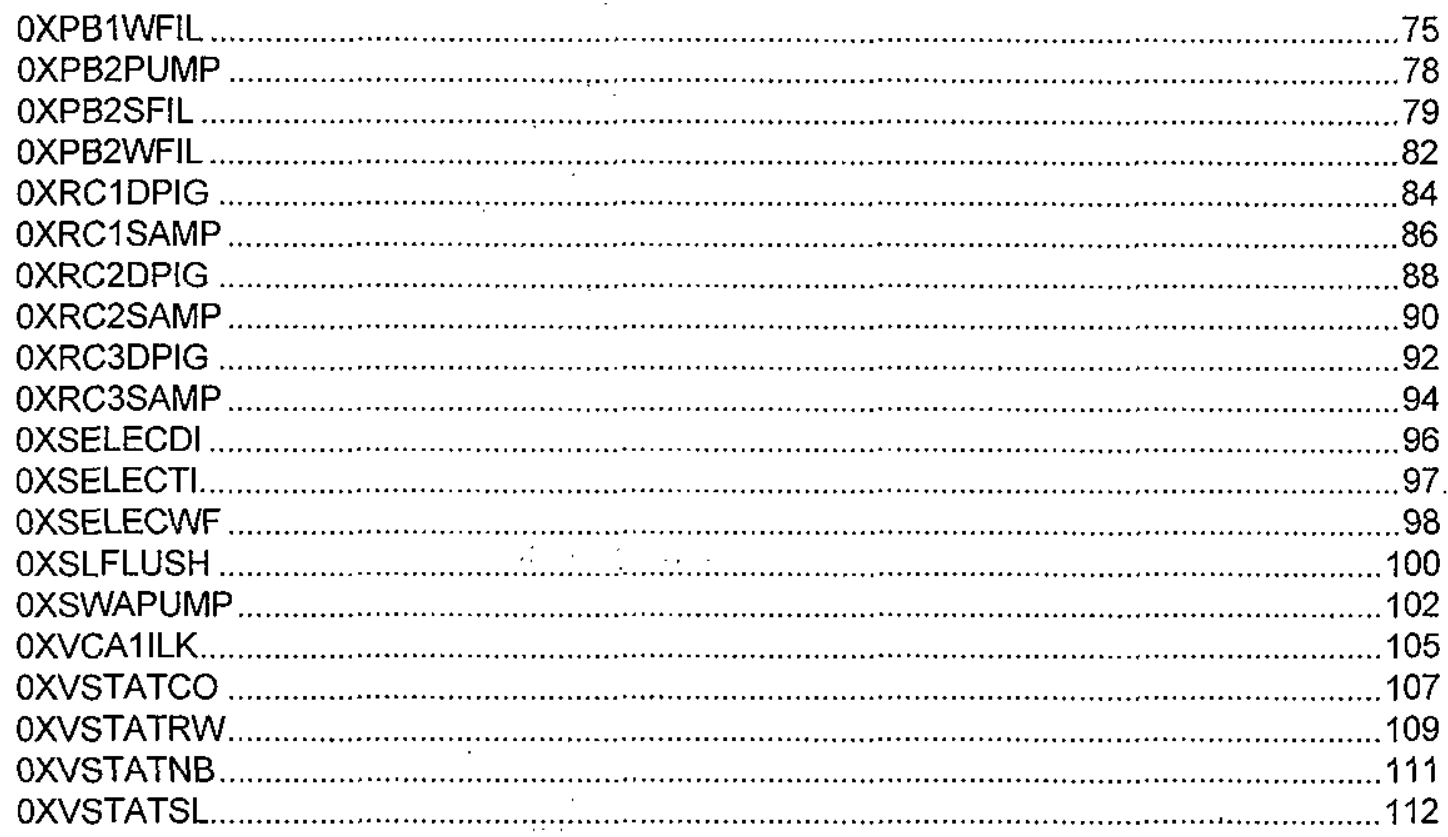

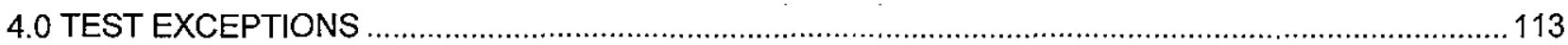

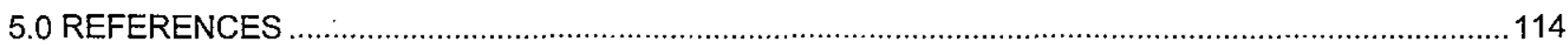

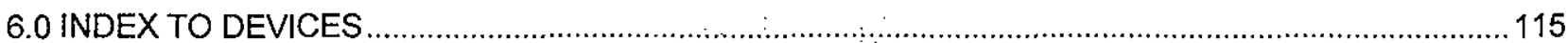

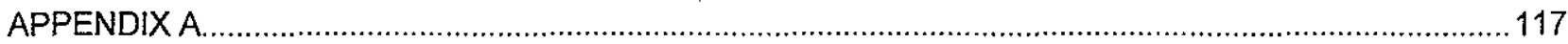

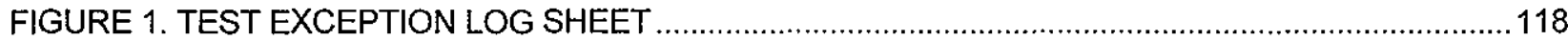




\section{ACCEPTANCE TEST REPORT SUMMARY}

This test was performed per HNF-3568, 242-A MCS LOGIC ACCEPTANCE TEST PROCEDURE FOR YEAR 2000 UPGRADE. The test was performed in Baltimore, MD, at the factory of the control system supplier. The test was conducted using a simulation database, where software addresses to hardwired input signals were modified to accept simulated inputs.

As the test was performed, displays that showed the information necessary to verify the test results were brought to the screen of the operator workstation. When the results were verified, the appropriate verification blocks on the test data sheets contained herein were initialed. After all the required information on each test data sheet was verified, the test data sheet was then signed and dated.

There were no exceptions exposed during testing that could not be resolved or explained. There were three exceptions (see page 118) that were the direct result of testing with a simulation database. Each exception involved the Device FAULT bit. When the real hardware input addresses were used instead of the simulated inputs, the FAULT bit operated normally. Therefore, these exceptions are accepted as-is. Otherwise, the system, logic, batch programs, and C-language programs responded correctly to all testing and meets the requirements to operate the 242-A Evaporator facility.

ACCEPTANCE TEST REPORT APPROVALS:
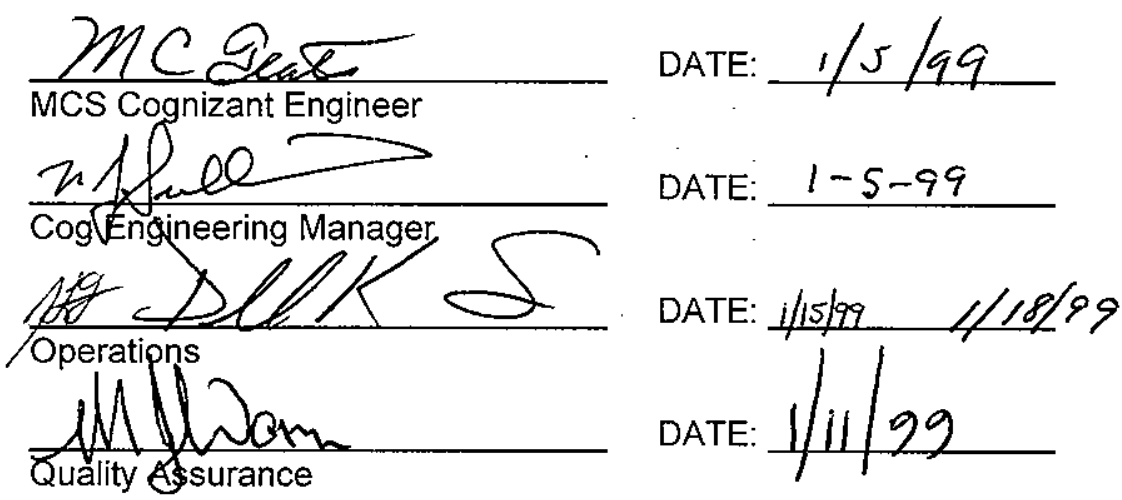


\subsection{INTRODUCTION}

The 242-A Evaporator Monitor and Control System (MCS) is being upgraded to meet Year 2000 requirements. This software Acceptance Test Report (ATR) documents validation of the evaporator logic and other applications for the MCS. A separate test procedure (Reference 1) will be performed to verify Year 2000 compliance.

\subsection{TEST PLAN}

This ATP was performed at the factory of the control system manufacturer and/or at the 242-A Evaporator Building. After testing at the factory, the new equipment provided by the upgrade project will be moved to the 242-A Evaporator Building for installation. The ability to conduct this ATP at the factory depends on the vendor providing the necessary hardware, primarily Process Control Modules (PCMs). In the event the vendor is unable to provide the necessary equipment, the ATP may be completed after the MCS is moved and installed at the 242-A Evaporator Building.

The test data sheets containing the results of the testing are documented herein.

\subsection{TEST PERSONNEL AND RESPONSIBILITIES}

The cognizant engineering manager shall appoint a test coordinator and test performers for the duration of the ATP. The test coordinator shall be responsible for scheduling the various parts of the test and notifying participants when testing will commence. Test performers will be responsible for performing the test and recording the test results on the data sheets.

The test coordinator and test performers will be individuals who are knowledgeable of the MCS. The test coordinator and performers shall have a working knowledge of various system operations including the operator console keyboard, and the software utilities and editors that are used to construct the application databases, programs, and displays. Performance of this test also requires knowledge of how logic devices function, including their interactions.

\subsection{TEST METHODS}

Testing will be performed using a computer simulation of the process or by actual operation of plant equipment. In either case, the logic will be functionally tested for correctness of operation.

Section 3 contains the specific tests to be performed and the associated data sheets. With few exceptions, the order in which the tests are performed is unimportant. Each section also provides specific details regarding the testing methods to be employed. 


\subsection{TEST PROCEDURE}

\subsection{ALARM PROGRAM TESTING}

Field input signals are distributed between 26 sequence units. For each unit there is one sequence program that processes the alarms. One or more alarms for each unit will be tripped to verify proper operation of the sequence program, several $\mathrm{C}$ programs, the annunciator lamp, acknowledgement, and clearing of alarms.

Each sequence program and supporting C programs (DOG0A, DOG0B, DOG1A, or DOG1B; and WATCH) will be tested by generating one alarm in each sequence unit to verify the following features:

- Lamp blinks on alarm

- Selecting lamp button displays correct graphic

- Flashing alarm message displayed in graphic

- Acknowledging the alarm makes the message go steady in graphic

- Acknowledging the alarm makes the lamp go steady

- Acknowledging the alarm makes other flashing alarm indications go steady (P lists, faceplates)

- Clearing of alarm makes graphic message disappear or turn to normal color (such as green)

- Clearing of alarm makes lamp turn off (if no other alarms in the sequence unit), or

- Clearing of alarm has no effect on lamp (if other alarms are active in the sequence unit)

Sequence programs that perform other functions such as EPN on/off (TAG), time for inhibit program (INHA), and time for program status (PGMOA, PGM1A) will be verified by viewing their respective graphic displays for correctness of information. 


\subsubsection{SEQUENCE ALARM PROGRAM TEST DATA SHEET}

\begin{tabular}{|c|c|}
\hline SABL PROGRAM NAME & PROGRAM VERIFIED \\
\hline 224BATCH & MT $12 / 19 / 98$ \\
\hline 244HVAC & mi $12 / 19 / 98$ \\
\hline WSTXFR & MT $12 / 19 / 98$ \\
\hline 350BATCH & MT $12 / 19 / 98$ \\
\hline FEEDBATCH & MT $12 / 19 / 98$ \\
\hline CA1BATCH & MT $\quad 12 / 19 / 58$ \\
\hline PB1BATCH & MT $\quad 12 / 19 / 98$ \\
\hline PB2BATCH & MT $12 / 19 / 98$ \\
\hline EA1BATCH & MT $12 / 19 / 98$ \\
\hline EC1BATCH & MT $12 / 19 / 98$ \\
\hline RWBATCH & MT $12 / 19 / 58$ \\
\hline URWBATCH & $m \tau \quad 12 / 19 / 98$ \\
\hline VENTBATCH & $m \sigma \quad 12 / 19 / 98$ \\
\hline PCBATCH & MT $12 / 19 / 98$ \\
\hline IXBATCH & $M T \quad 12 / 19 / 98$ \\
\hline SCBATCH & MT $12 / 19 / 98$ \\
\hline BASINBAT & MT $12 / 19 / 98$ \\
\hline UTILBATCH & MT $12 / 19 / 98$ \\
\hline AMUBATCH & mT $12 / 19 / 98$ \\
\hline LERFBATCH & $m T \quad 12 / 19 / 98$ \\
\hline CASSBATCH & $m \sigma^{\circ} \quad 12 / 19 / 98$ \\
\hline TAG & $m \tau \quad 12 / 19 / 98$ \\
\hline TIMEINHA & mT $12 / 18 / 98$ \\
\hline PGMOA & MT a//8/98 \\
\hline WHITE1 & MT $\quad 2 / 18 / 98$ \\
\hline ANBATCH & MT $12 / 19 / 98$ \\
\hline APBATCH & MT $12 / 19 / 98$ \\
\hline AWBATCH & $M T \quad 12 / 19 / 98$ \\
\hline XYZBATCH & $m+12 / 19 / 98$ \\
\hline 242BATCH & $m T 2 / 19 / 98$ \\
\hline PGM1A & $M T 12 / 19 / 98$ \\
\hline
\end{tabular}

TESTED BY hy Sectoto DATE $12 / 19 / 98$

* 10 sec for skid to light up 15 sec for white skid 


\subsubsection{ALARM PROGRAM TEST DATA SHEET}

\begin{tabular}{|l|c|}
\hline C PROGRAM NAME & PROGRAM(S) VERIFIED \\
\hline $\begin{array}{l}\text { DOGOA, DOGOB, } \\
\text { DOG1A, or DOG1B }\end{array}$ & $12 / 19 / 98 \mathrm{MP}$ \\
\hline WATCH & $12 / 19 / 98 \mathrm{MT}$ \\
\hline
\end{tabular}

tested вy Date in/19/98 


\subsection{MISCELLANEOUS C PROGRAM TESTING}

The following $\mathrm{C}$ programs will be functionally tested.

C PROGRAM NAME FQIRESET

INHA

UKF14

UKF34

UKF43

BALANCE

TFBAL
FUNCTIONAL DESCRIPTION

Automatically Resets Totalizers

Generates List Of Inhibited Alarms For Graphics

Regenerates All Alarms For P1 \& P2 Summaries

Removes Inhibits From 242-A Alarms For Startup Inhibits 242-A Alarms For Shutdown

Performs 242-A Building Material Balance

Performs Tank Farm Transfer Balance

\subsubsection{MISCELLANEOUS C PROGRAM TEST DATA SHEET}

\begin{tabular}{|l|ll|}
\hline C PROGRAM NAME & PROGRAM VERIFIED \\
\hline INHA & $12 / 18 / 98$ & $M T$ \\
\hline UKF14 & $12 / 18 / 98$ & $M T$ \\
\hline UKF34 & $12 / 19 / 98$ & $M T$ \\
\hline UKF43 & $12 / 19 / 98$ & $M T$ \\
\hline BALANCE & $12 / 21 / 98$ & $M T$ \\
\hline TFBAL & $12 / 22 / 98$ & $M T$ \\
\hline FQIRESET & $12 / 18 / 98$ & $M T$ \\
\hline
\end{tabular}

TESTED BY M Seato DATE $12 / 22 / 98$ 


\subsection{DEVICE LOGIC TESTING}

In the MCS database, a "master device" is a unique set of interconnected logic blocks such as AND, OR, NOT, and time delays. Each application of the master device to specific equipment is a device. Devices do not contain logic elements, but are linked to master device logic. Interlocks that are specific to a device are linked to the master device by assignment of input addresses in the device. A device is also linked to field equipment by assignment of input and output addresses. Verification of all software input and output addresses was completed in previous acceptance tests (References 2,3 ) and operability tests (Reference 4) and shall not be duplicated in this ATP. The purpose of the logic testing in this ATP is to verify that new vendor software obtained by the MCS upgrade has not changed the way the logic works.

This does not mean that all logic must be tested. In fact, the philosophy of this ATP is not to conduct $100 \%$ testing of the logic, but to spot check logic for proper operation. If each of the basic logic elements function correctly, then all logic can be declared valid. This eliminates the need to test all of the logic, such as logic for the Tank Farm equipment. It also eliminates the need to test every interlock in a given device. in cases where there are multiple interlocks in a device, only one interlock needs to be triggered to observe the correct logic response.

Any number of devices may share the same master device logic. For this reason, it is not necessary to test every device that shares a common master device to validate the logic for the master device. However, if interlocks are involved, then at least one of the interlocks to a device must be tested. Examples of devices that share the same master device logic and do not contain interlocks are the steam condensate basin valves, which share master device OV1M1SOON.

All device logic is documented in the $\mathrm{H}-2-99949$ drawing series. This test document contains the information necessary to verify the operation of the devices. The software (code) for the devices determines their configuration at the time of testing. Changes to the code will be controlled after testing commences and documented by Engineering Change Notice.

Test data sheets for devices are contained in this section of the ATP. Each device also has a functional description including the commands and statuses in the operator displays and keyboard. For all discrete inputs the expected interlock or active state (" 0 " or "1") is specified. A " 0 " is the absence of a simulated signal or absence of voltage. $A$ " 1 " is the presence of a simulated signal or presence of voltage at the input. For analog signals the interlock or active level is given in engineering units. The analog faceplate display indicates the current value in engineering units. When this measured value exceeds the limit, the interlock must activate.

The devices can be tested in any order, however, since some devices interact with others, they must be tested simultaneously. It will be the responsibility of the test performer to anticipate these interactions and order the testing accordingly. These interactions are listed on the data sheets as inputs and/or outputs. 


\section{HNF-3569 REV 0}

\subsubsection{PCMO DEVICE DESCRIPTIONS AND DATA SHEETS}

This section contains the device descriptions and data sheets for devices in PCMO. They are presented in alphabetical order by master device name. An index by device name can be found at the end of this ATP. 


\section{MASTER DEVICE 010M1S20N}

DEV(S): $\quad$ EA1-INLK1

DRAWING: $\mathrm{H}-2-99949 \mathrm{SHT} 12$

DESCRIPTION: This device is used to bypass the recirculation line high and low flow interlocks to the reboiler steam/air valve (FV-EA1-1).

COMMANDS:

CO NOBYPASS: Turns off the bypass condition.

C1 BYPASS: Turns on the bypass condition.

AUTO/MAN: Auto locks out all commands. Device should always be in Manual.

INTERLOCKS: This device has two interlocks.

OVERRIDE: OVERRIDE (Override Key) has no effect on this master device.

STATUSES:

SO NOBYPASS: Not in bypass.

S1 BYPASS: $\quad$ Bypass condition is on.

S5 INTERLOK: $\quad$ High or Low flow condition (interlocks steam in Device FV-EA1-1 unless in BYPASS).

FAULT: $\quad$ Not used on this device. 
HNF-3569 REV 0

TEST DATA SHEET

DEVICE: EA1-INLK1

INTERLOCKS

$\begin{array}{lll}\begin{array}{ll}\text { EPA } \\ \text { FI-CA1-3 }\end{array} & \begin{array}{l}\text { VALUE } \\ \text { FI-CA1-3 }\end{array} & \begin{array}{l}\text { DESCRIPTION } \\ \text { Recirculation Line Flow Hi } \\ \text { Recirculation Line Flow Lo }\end{array} \\ \begin{array}{l}\text { OUTPUTS } \\ \text { DESTN }\end{array} & \frac{\text { VALUE }}{\text { \$G7 }} & \frac{\text { DESCRIPTION }}{\text { Passes Interlock Condition to FV-EA1-1 }}\end{array}$

MT Verify that any one of the interlocks are passed to FV-EA1-1 when not bypassed.

MT Verify that command 0 turns off the bypass condition.

$M T$ Verify that command 1 turns on the bypass condition.

TESTED BY M. Seat DATE 12/19/98

13 


\section{MASTER DEVICE 010M1S44N}

DEV(S): PC-INLK1

DRAWING: $\quad \mathrm{H}-2-99949 \mathrm{SH} \Gamma 22$

DESCRIPTION: This device is used to bypass up to four interlocks that are passed to another device. It also monitors a hardware bypass switch and goes to the BYPASS state whenever the switch is in bypass. When the hardware switch is moved from bypass to normal, the device is placed in NOBYPASS status, however, it can be returned to BYPASS using the $\mathrm{C} 1$ command.

COMMANDS:

CONOBYPASS: Puts the device into NOBYPASS status unless the hardware bypass switch is in the bypass position.

C1 BYPASS: $\quad$ Puts the device into BYPASS status.

AUTO/MAN: $\quad$ Auto locks out all commands. Device should always be in Manual.

INTERLOCKS: This device has four interlocks.

OVERRIDE: $\quad$ OVERRIDE (Override Key) has no effect on this master device.

STATUSES:

SO NOBYPASS: Not in bypass.

S1 BYPASS: $\quad$ Bypass condition is on.

S5 INTERLOK: An interlock condition exists and is being passed to another device unless in BYPASS.

FAULT: $\quad$ Not used on this device. 


\section{HNF-3569 REV 0}

\section{TEST DATA SHEET}

DEVICE: PC-INLK1

INTERLOCKS

EPN VALUE DESCRIPTION

RI-RC3-1 $45 \quad$ Process Condensate. Rad Hi

RI-CA1-1 $8000 \quad$ Process Condensate Line Rad Hi

RSH-RC3-1 "0" Process Condensate Rad Hi

$\mathrm{RSH}-\mathrm{CA1}-1$ "0" Process Condensate Line Rad Hi

OUTPUTS

DESTN VALUE DESCRIPTION

$\frac{\text { \$G13 }}{0 / 1} \quad$ Passes Interlock Condition to P-C100

$M T$ Verify that any one of the interlocks are passed to P-C100 when not bypassed.

$M T$ Verify that command 0 turns off the bypass condition.

$M T$ Verify that command 1 turns on the bypass condition.

TESTed By makate DATE_12/19/98 


\section{HNF-3569 REV 0}

\section{MASTER DEVICE 010M1S60N}

DEV(S): PC-INLK2

DRAWING: $\quad \mathrm{H}-2-99949$ SHT 22

DESCRIPTION: This device is used to pass interlocks to device P-C100. There are no bypasses or commands.

COMMANDS: None.

AUTOIMAN: None.

INTERLOCKS: This device has several interlocks.

OVERRIDE: OVERRIDE (Override Key) has no effect on this master device.

STATUSES:

S5 INTERLOK: An interlock condition exists and is being passed to another device unless in BYPASS.

FAULT: $\quad$ Not used on this device. 
HNF-3569 REV 0

TEST DATA SHEET

DEVICE: PC-INLK2

INTERLOCKS

$$
\begin{aligned}
& \text { lPN } \frac{\text { VALUE }}{12} \text { DESCRIPTION. } \\
& \text { PDI-IDX-2 } 12 \quad \text { IDX Col Upper Screen DP Hi } \\
& \text { PDI-IDX-3 } 18 \quad \text { IDX Col Lower Screen DP Hi } \\
& \text { PDI-IDX-5 } 30 \quad \text { IDX Co Overall DP Hi } \\
& \text { WFIC-C100 } 27 \\
& \text { PDI-ILS-1 } 40 \\
& \text { TK-C-100 aF LO } \\
& \text { FC-3 Filter DP Hi } \\
& \text { PDI-FC1-1 } 40 \quad \text { FC-1 Filter DP Hi } \\
& \text { OUTPUTS } \\
& \frac{\text { DESTN }}{\$ G 13} \quad \frac{\text { VALUE }}{0 / 1} \quad \frac{\text { DESCRIPTION }}{\text { Passes Interlock Condition to P-C } 100}
\end{aligned}
$$

MT Verify that any one of the interlocks are passed to P-C100 when not bypassed.

$N / A$ No bypasses or commands $\mathrm{N} / \mathrm{A}$ verify ir /19/98 are programmed (sec piG)

TESTED BY Mấ⿺辶⿻ DATE $12 / 19 / 98$

17 


\section{MASTER DEVICE 0M1M2P11S}

$$
\text { DEV(S): A-E-101 P-E-101 A-E-102 P-E-102 A-E-104 P-E-104 }
$$

DRAWING: $\mathrm{H}-2-99949$ SHTS $31,32,33,34,35$, and 36

DESCRIPTION: Controls the operation of a motor with contact confirm. Two pulsed outputs are used - one for START and one for STOP. This master device is used for motors that have a remote manual start/stop station.

\section{COMMANDS:}

CO STOP:

C1 START:

C2 SD-RESET:

AUTO/MAN:

INTERLOCKS:

OVERRIDE:

STATUSES:

SO CF-OFF:

S1 CF-ON:

S2 SD-RESET:

S4 SHUTDOWN:
Stops the motor.

Starts the motor provided there is no interlock.

Resets the SHUTDOWN status and causes the STOP command to follow. If this status is alarmed, it will clear the alarm.

Auto locks out all commands. Device should always be in Manual.

This master device has one interlock. When active, the interlock will cause the stop output to remain open continuously thereby preventing manual starting of the motor.

OVERRIDE (Override Key) causes the confirms to be ignored and will therefore clear the FAULT condition if it is present.

Not running as confirmed by the motor contactor or current.

Running as confirmed by the motor contactor and current.

Temporary status during resetting of the SHUTDOWN status.

The motor has stopped as confirmed by the contactor without being commanded to stop. This could be due to an interlock (as indicated by the INTERLOK status) or due to some abnormal condition not monitored by the device (remote stop). If no interlock is present after SHUTDOWN, attempting to restart the motor may result in a FAULT condition.

S5 INTERLOK: Indicates an interlock condition is present.

S6 STOPPING: The motor has been commanded to stop but the contact is still present.

S7 STARTING: The motor has been commanded to start but the contact confirm has not been received yet.

FAULT: The device will fault when it does not start or stop within the allowable time period after the associated command is issued. The FAULT condition can be cleared by going to OVERRIDE (Override Key). 


\section{TEST DATA SHEET}

DEVICE: A-E-101

INTERLOCKS: A-E-101 Stops and will not start on interlock.

$\frac{\text { EPN }}{\text { WFI-E101 }} \frac{\text { VALUE }}{25} \quad \frac{\text { DESCRIPTION }}{\text { Eluant Tank WF LO }}$

CONFIRMS:

$\frac{\text { EPN }}{\text { YS-A-E101 }} \frac{\text { VALUE }}{\text { "1" }} \quad \frac{\text { DESCRIPTION }}{\text { Confirm on }}$

\section{OUTPUTS}

DESTN

?OUT1

?OUTO

VALUE DESCRIPTION

NO Start Pulse

FAULI

NC

Stop Pulse

TEST EXCEPTION 43

\section{OTHER TESTS OR EXPLANATION:}

$M T$ Verify that the interlock stops motor and prevents starting of motor.

$m v$ Verify that command 0 turns off the motor.

$m$ Verify that command 1 turns on the motor.

$M \nabla$ Verify that command 2 resets the shutdown of the motor following interlock.

TESTED BY MOknto DATE $12 / 19 / 98$ 
DEVICE: P-E-101

INTERLOCKS: P-E-101 Stops and will not start on interlock.

$\frac{\text { EPN }}{\text { WFI-E101 }} \frac{\text { VALUE }}{15} \quad \frac{\text { DESCRIPTION }}{\text { Eluant Tank WF Lo-Lo }}$

CONFIRMS

$\frac{\text { EPN }}{\text { YS-P-E101 }} \frac{\text { VALUE }}{\text { "1" }} \quad \frac{\text { DESCRIPTION }}{\text { Confirm on }}$

OUTPUTS

\begin{tabular}{|c|c|c|}
\hline DESTN & VALUE & DESCRIPTION \\
\hline ?OUT1 & NO & Start Pulse \\
\hline ?OUTO & NC & Stop Pulse \\
\hline
\end{tabular}

FAULT OVERRIDE $N / A$

TEST EXCEATION \$3

\section{OTHER TESTS OR EXPLANATION:}

$M T$ Verify that the interlock stops motor and prevents starting of motor.

$M I$ Verify that command 0 turns off the motor.

$M V$ Verify that command 1 turns on the motor.

$M T$ Verify that command 2 resets the shutdown of the motor following interlock.

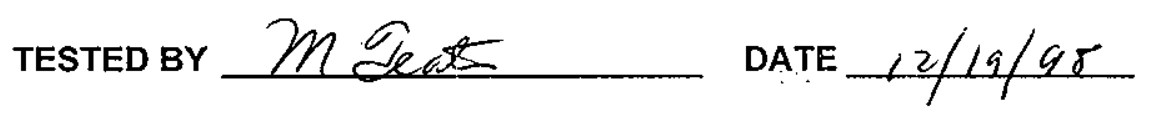




\section{HNF-3569 REV 0}

\section{TEST DATA SHEET}

DEVICE: A-E-102

INTERLOCKS: A-E-102 Stops and will not start on interlock.

$\frac{\text { EPN }}{\text { WFI-E102 }} \frac{\text { VALUE }}{12} \quad \frac{\text { DESCRIPTION }}{\text { Anti-Foam Tank WF Lo }}$

CONFIRMS

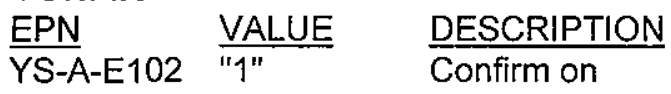

OUTPUTS

DESTN

?OUT1

VALUE DESCRIPTION

?OUTO

NO Start Pulse

NC Stop Pulse

TEST EXCEPTION \#3

FAULT OVERRIDE $N / A$

\section{OTHER TESTS OR EXPLANATION:}

HAT Verify that the interlock stops motor and prevents starting of motor.

MT Verify that command 0 turns off the motor.

$m$ Verify that command 1 turns on the motor.

$m$ Verify that command 2 resets the shutdown of the motor following interlock.

TESTED BY Makate DATE_12/19/98 


\section{HNF-3569 REV 0}

\section{TEST DATA SHEET}

DEVICE: P-E-102

INTERLOCKS: P-E-102 Stops and will not start on interlock.

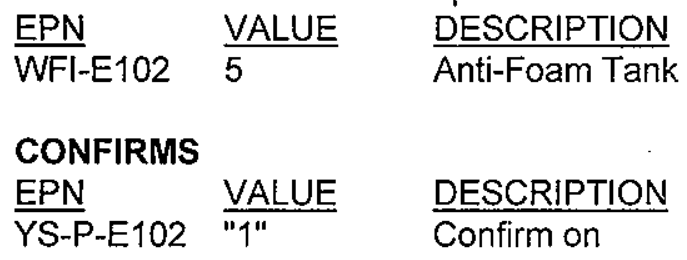

OUTPUTS

$\begin{array}{lll}\text { DESTN } & \text { VALUE } & \text { DESCRIPTION } \\ \text { ?OUT1 } & \text { NO } & \text { Start Pulse } \\ \text { ?OUTO } & \text { NC } & \text { Stop Pulse }\end{array}$

FAULT OVERRIDE N/A

TEST EXCEPTION H3

\section{OTHER TESTS OR EXPLANATION:}

$M T$ Verify that the interlock stops motor and prevents starting of motor.

$M T$ Verify that command 0 turns off the motor.

$M \mp$ Verify that command 1 turns on the motor.

$m T$ Verify that command 2 resets the shutdown of the motor following interlock.

TESTED BY M. Sest DATE $12 / 19 / 98$ 


\section{TEST DATA SHEET}

DEVICE: A-E-104

INTERLOCKS: A-E-104 Stops and will not start on interlock.

$\frac{\text { EPN }}{\text { WFI-E104 }} \frac{\text { VALUE }}{12} \quad \frac{\text { DESCRIPTION }}{\text { Decon Tank WF Lo }}$

CONFIRMS

$\frac{\text { EPN }}{\text { YS-A-E104 }} \frac{\text { VALUE }}{\text { "1" }} \quad \frac{\text { DESCRIPTION }}{\text { Confirm on }}$

OUTPUTS

DESTN

?OUT1

VALUE $\quad$ DESCRIPTION

?OUTO

Start Pulse

Stop Pulse

FAULT OVERRIDE U/A

TEST EXCEPTION \#3

\section{OTHER TESTS OR EXPLANATION:}

$M T$ Verify that the interlock stops motor and prevents starting of motor.

$M T$ Verify that command 0 turns off the motor.

$m \mathcal{L}$ Verify that command 1 turns on the motor.

$M T$ Verify that command 2 resets the shutdown of the motor following interlock.

TESTED BY M. Defeto DATE_-12/19/98 


\section{HNF-3569 REV 0}

TEST DATA SHEET

DEVICE: P-E-104

INTERLOCKS: P-E-104 Stops and will not start on interlock

EPN VALUE DESCRIPTION

WFI-E104 5 Decon Tank WF Lo-Lo

CONFIRMS

$\frac{\text { EPN }}{\text { YS-P-E104 }} \frac{\text { VALUE }}{\text { "1" }} \quad \frac{\text { DESCRIPTION }}{\text { Confirm on }}$

OUTPUTS

DESTN VALUE DESCRIPTION

?OUT1 NO Start Pulse

?OUTO NC Stop Pulse

FAULT OVERRIDE $\triangle 1 / A$ (TEST EXCEPTION

\section{OTHER TESTS OR EXPLANATION:}

$m$ Verify that the interlock stops motor and prevents starting of motor.

MT Verify that command 0 turns off the motor.

$m T$ Verify that command 1 turns on the motor.

$M T$ Verify that command 2 resets the shutdown of the motor following interlock.

tested By M. Neates Date $12 / 19 / 98$ 


\section{MASTER DEVICE OM2M1S11S}

$\operatorname{DEV}(\mathrm{S}): \quad \mathrm{A}-\mathrm{C} 100$

DRAWING: H-2-99949 SHTS 23 and 42

DESCRIPTION: Controls the operation of a motor with both current and contact confirm. This master device has one interlock.

\section{COMMANDS:}

CO STOP: $\quad$ Stops the motor.

C1 START: $\quad$ Starts the motor provided there is no interlock.

C2 SD-RESET: Resets the SHUTDOWN status and causes the STOP command to follow. If this status is alarmed, it wil! clear the alarm.

AUTO/MAN: $\quad$ Auto locks out all commands. Device should always be in Manual.

INTERLOCKS: This master device has one interlock.

OVERRIDE: $\quad$ OVERRIDE (Override Key) causes the confirms to be ignored and will therefore clear the FAULT condition if it is present.

\section{STATUSES:}

SO CF-OFF: $\quad$ Not running as confirmed by the motor contactor or the motor current.

S1 CF-ON: $\quad$ Running as confirmed by the motor contactor and the motor current.

S2 SD-RESET: Temporary status during resetting of the SHUTDOWN status.

S4 SHUTDOWN: The motor has stopped as confirmed by the contactor or motor current without being commanded to stop. This could be due to an interlock (as indicated by the INTERLOK status) or due to some abnormal condition not monitored by the device. If no interlock is present after SHUTDOWN, attempting to restart the motor may result in a FAULT condition.

S5 INTERLOK: Indicates an interlock condition is present.

S6 STOPPING: The motor has been commanded to stop but the contact and motor current confirm are still present.

S7 STARTING: The motor has been commanded to start but the contact and current confirms have not been received yet.

FAULT: The device will fault when it does not start or stop within the allowable time period after the associated command is issued. The FAULT condition can be cleared by going to OVERRIDE (Override Key). 


\section{HNF-3569 REV 0}

\section{TEST DATA SHEET}

DEVICE: A-C100

INTERLOCKS: A-C100 Stops and will not start on interlock.

\begin{tabular}{|c|c|c|}
\hline$\frac{E P N}{W F I C-C 100}$ & $\frac{\text { VALUE }}{27}$ & $\frac{\text { DESCRIPTION }}{\text { TK-C-100 WF LO }}$ \\
\hline \multicolumn{3}{|l|}{ CONFIRMS } \\
\hline EPN & VALUE & DESCRIPTION \\
\hline II-A-C100 & $\begin{array}{l}3 \\
31 "\end{array}$ & Motor Current Confirm \\
\hline YS-A-C100 & "1" & \\
\hline
\end{tabular}

\section{OUTPUTS}

DESTN VALUE DESCRIPTION

?OUT1 NO Motor Start(1)/Stop(0)

FAULY OVERRIDE N/A T.E \#3 $12 / 19 / 98$

$M T$ Verify that the interlock stops motor and prevents starting of motor.

$m T$ Verify that command 0 turns off the motor.

$m_{T}$ Verify that command 1 turns on the motor.

$M T$ Verify that command 2 resets the shutdown of the motor following interlock.

TESTED BY Masets

DATE $12 / 19 / 98$ 


\section{HNF-3569 REV 0 \\ MASTER DEVICE OM2M1S77S}

DEV(S): P-AW-102

DRAWING: $\quad \mathrm{H}-2-99949$ SHT 37

DESCRIPTION: Controls the operation of a motor with both current and contact confirm. This master device has up to seven interlocks.

COMMANDS:

CO STOP: Stops the motor.

C1 START: $\quad$ Starts the motor provided there is no interlock.

C2 SD-RESET: Resets the SHUTDOWN status and causes the STOP command to follow. If this status is alarmed, it will clear the alarm.

AUTO/MAN: $\quad$ Auto locks out all commands. Device should always be in Manual.

INTERLOCKS: This master device can have up to seven interlocks. These devices all have hardwired interlocks also.

OVERRIDE: $\quad$ OVERRIDE (Override Key) causes the confirms to be ignored and will therefore clear the FAULT condition if it is present.

STATUSES:

SO CF-OFF:

Not running as confirmed by the motor contactor or the motor current.

S1 CF-ON: $\quad$ Running as confirmed by the motor contactor and the motor current.

S2 SD-RESET: Temporary status during resetting of the SHUTDOWN status.

S4 SHUTDOWN: The motor has stopped as confirmed by the contactor or motor current without being commanded to stop. This could be due to an interlock (as indicated by the INTERLOK status) or due to some abnormal condition not monitored by the device. If no interlock is present after SHUTDOWN, attempting to restart the motor may result in a FAULT condition.

S5 INTERLOK: Indicates an interlock condition is present.

S6 STOPPING: The motor has been commanded to stop but the contact and motor current confirm are still present.

S7 STARTING: The motor has been commanded to start but the contact and current confirms have not been received yet.

FAULT: The device will fault when it does not start or stop within the allowable time period after the associated command is issued. The FAULT condition can be cleared by going to OVERRIDE (Override Key). 


\section{HNF-3569 REV 0}

\section{TEST DATA SHEET}

DEVICE: P-AW-102

INTERLOCKS: P-AW-102 Stops and will not start on interlock.

\begin{tabular}{|c|c|c|}
\hline EPN & VALUE & DESCRIPTION \\
\hline$\overline{\mathrm{LI}-\mathrm{CA}} 1-1$ & 65.8 & 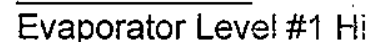 \\
\hline LI-CA1-2 & 65.45 & Evaporator Level \#2 $\mathrm{Hi}$ \\
\hline RI-CA1-1 & 8000 & PC Line Rad Hi \\
\hline PDI-CA1-1 & 4.5 & Lower De-Entrainmen \\
\hline PDI-CA1-2 & 4.5 & Upper De-Entrainmen \\
\hline YSAW102!L & "0" & Hardwired Interlock Sta \\
\hline$\$ G 14$ & "0" & Interlock from EX-C-1 \\
\hline \multicolumn{3}{|l|}{ CONFIRMS } \\
\hline EPN & VALUE & DESCRIPTION \\
\hline$\overline{\mathrm{II}-\mathrm{AW}}-102$ & 5 & Current Confirn \\
\hline YS-AW102 & "1" & Moto \\
\hline
\end{tabular}

OUTPUTS

DESTN VALUE DESCRIPTION

?OUT1 NO Motor Start(1)/Stop(0)

FAULT OVERRIDE $\triangle$ ILA TEHS

$m \sigma$ Verify that the interlock stops motor and prevents starting of motor.

$m$ Verify that command 0 turns off the motor.

me Verify that command 1 turns on the motor.

$m J$ Verify that command 2 resets the shutdown of the motor following interlock.

TESTED BY M. Deats DATE 12/10/98 


\section{MASTER DEVICE OVOM1S11N}

DEV(S): TV-DSH1/2

DRAWING: $\mathrm{H}-2-99949 \mathrm{SHT} 13$

DESCRIPTION: This device controls a two-position valve with no limit switch confirmation for either position.

COMMANDS:

CO CLOSE: Closes the valve.

C1 OPEN: $\quad$ Opens the valve.

AUTO/MAN: . Auto locks out all commands. Device should always be in MANUAL.

INTERLOCKS: This device has one interlock. When steam valve FV-EA1-1 is closed, it forces TVDSH-1/2 to close also. This interlock is also hardwired.

OVERRIDE: $\quad$ Not used in this device.

STATUSES:

SO CLOSED: Valve has been commanded to close (no confirmation).

S1 OPEN: $\quad$ Valve has been commanded to open (no confirmation).

S5 INTERLOK: An interlock is present.

FAULT: Not used on this device. 
HNF-3569 REV 0

TEST DATA SHEET

\section{DEVICE: TV-DSH $1 / 2$}

INTERLOCKS: TV-DSH $1 / 2$ Closes on interlock and will not Open.

$\frac{\text { EPN }}{\text { ZS-EA1-C }} \quad$ VALUE $\quad \frac{\text { DESCRIPTION }}{\text { Steam valve FV-EA1-1 closed }}$

OUTPUTS

DESTN VALUE DESCRIPTION

?OUT1 NO Open TV-DSH1/2

$M T$ Verify that the interlock closes valve and prevents opening of valve.

$M T$ Verify that command 0 closes valve.

MI Verify that command 1 opens valve.

TESTED BY XM Teat DATE $12 / 19 / 98$ 


\section{MASTER DEVICE OV1M0S22}

$\operatorname{DEV}(\mathbf{s}): \quad H V-C A 1-10$

DRAWING: $\mathrm{H}-2-99949$ SHT 55.

DESCRIPTION: Valve controller with two confirms on position, manual operation only, no local control, one output, standard state, two interlocks.

COMMANDS:

CO CLOSE: $\quad$ Positions valve to filtered raw water (FRW).

C1 OPEN: $\quad$ Positions valve to recycle process condensate (PC).

C2 CS-RESET: Resets the CHGSTATE. status and causes the FRW $(\$ C 0)$ command to follow. If this status is alarmed, it will clear the alarm.

AUTO/MAN: $\quad$ Auto locks out all commands. Device should always be in Manual.

INTERLOCKS: ' This master device has two interlocks.

OVERRIDE: OVERRIDE (Override Key) causes the confirm to be ignored and will therefore clear the FAULT condition if it is present.

\section{STATUSES:}

So CF-FRW: $\quad$ Set to FRW as confirmed by analog Z1-CA1-10.

S1 CF-PC: $\quad$ Set to PC-recycle as confirmed by analog ZI-CA1-10.

S2 CS-RESET: Temporary status during resetting of the CHGSTATE status.

S4 CHGSTATE: The valve went to FRW as determined by the CF-PC confirm without being commanded to do so. This could be due to an interlock or some undetected abnormality. If no interlock is present, attempting to reposition the valve may result in a FAULT condition.

S5 INTERLOK: $\quad$ An interlock is present which prevents closing the valve.

S6 TRVLTORW: Status when the device has been commanded to FRW but the full-FRW confirmation has not been received yet.

S7 TRVLTOPC: $\quad$ Status when the device has been commanded to PC but the full-PC confirmation has not been received yet.

FAULT: The device will fault when the open/closed status does not agree with the command (after appropriate delay). The fault alarm can be cleared with OVERRIDE. 
TEST DATA SHEET

DEVICE: HV-CA1-10

INTERLOCKS: HV-CA1-10 positions to FRW and will not go to the PC position on interlock.

EPN VALUE

PI-CA1-20

75

DESCRIPTION

P-C106

$\$ G 23(0)$

P.C106 discharge pressure Lo

P.-C106 shutdown

\section{CONFIRMS}

EPN

VALUE

ZI-CA1-10 10

ZI-CA1-10 90

DESCRIPTION
\$T30 Confirm Closed
\$T31 Confirm Open

OUTPUTS

$\frac{\text { DESTN }}{\text { ?OUTO }} \quad \frac{\text { DALUE }}{\text { NO }} \quad \frac{\text { TOSCRIPTION }}{\text { PC reycle (1) / To FRW }}$

$\mathrm{mWT}$ Verify that interlock positions valve to FRW.

$M T$ Verify that command 0 positions to filtered raw water.

MU Verify that command 1 opens positions to condensate recycle.

TESTED BY M Jecato DATE_12/19/98 


\section{MASTER DEVICE OV1M1SOON}

\section{DEV(s): HV-SC-1A HV-SC-2A HV-SC-3A HV-SC-1B HV-SC-2B HV-SC-3B}

DRAWING: H-2-99949 SHTS 25, 26, 28, and 29.

DESCRIPTION: Valve controller with confirm on close, manual operation only, no local control, one output, standard state, no interlocks.

COMMANDS:

CO CLOSE: $\quad$ Closes valve.

C1 OPEN: $\quad$ Opens valve.

AUTO/MAN: Auto locks out all commands. Device should always be in Manual.

INTERLOCKS: This master device has no interlocks.

OVERRIDE: $\quad$ OVERRIDE (Override Key) causes the confirm to be ignored and will therefore clear the FAULT condition if it is present.

\section{STATUSES:}

SO CF-CLOSD: Closed as confirmed by limit switch.

S1 OPEN: $\quad$ Valve is open or partially open. Only the closed position can be confirmed by the limit switch since the switch opens when the valve begins to open.

S6 CLOSING: Valve has been commanded to close but the confirm has not been received yet.

FAULT: The device will fault when the open/closed status does not agree with the command (after appropriate delay). The fault alarm can be cleared by going to OVERRIDE. The FAULT condition has a 30 -second timer instead of the usual five seconds since this is a MOV and has travel time. 
HNF-3569 REV 0

TEST DATA SHEET

DEVICE: HV-SC-1A, HV-SC-2A, HV-SC-3A, HV-SC-1B, HV-SC-2B, or HV-SC-3B

CONFIRMS

For Device EPN VALUE DESCRIPTION

HV-SC-1A ZS-SC-1FC "1" $\quad$ Confirm Closed

HV-SC-2A ZS-SC-2FC "1" Confirm Closed

HV-SC-3A ZS-SC-3FC "1" Confirm Closed

HV-SC-1B ZS-SC-1DC "1" Confirm Closed

HV-SC-2B ZS-SC-2DC "1" Confirm Closed

HV-SC-3B ZS-SC-3DC "1" Confirm Closed

OUTPUTS

DESTN VALUE DESCRIPTION

?OUT1 NO Opens valve

FAULT $M T$ OVERRIDE MI T.E."Z Override does clear FAULT.

$M T$ Verify that command 0 closes valve.

$m \mathcal{T}$ Verify that command 1 opens valve.

TESTED BY in seat

DATE $12 / 19 / 98$

34 


\section{MASTER DEVICE OV2M1R55S}

DEV(S): HV-EC1-1

DRAWING: $\mathrm{H}-2-99949 \mathrm{SHT}^{\top} 5$

DESCRIPTION: This master device controls a valve with both full-open and full-closed limit switch confirmation. On interlock occurrence, this valve will open (fail-open).

COMMANDS:

CO CLOSE:

Closes the valve provided no interlock is present.

C1 OPEN: $\quad$ Opens the valve.

C2 CS-RESET: Resets the CHGSTATE status and causes the OPEN command to follow. If this status is alarmed, it will clear the alarm:

AUTO/MAN: $\quad$ AUTO locks out all commands. The device should always be in MANUAL.

INTERLOCKS: This master device has five interlocks. Activation of any one or more of the interlocks will cause the valve to open. One of the five interlocks is passed from EX-C-1 via Global Bit G14. This device also has hardwired interlocks.

OVERRIDE: OVERRIDE (Override Key) causes the confirms to be ignored and will therefore clear the FAULT condition if it is present.

STATUSES:

SO CF-CLOSD: Closed as confirmed by the full-closed limit switch.

S1 CF-OPEN: . Open as confirmed by the full-open limit switch.

S2 CS-RESET: Temporary status during resetting of the CHGSTATE status.

S4 CHGSTATE: The valve opened as determined by the CF-OPEN confirm without being commanded to do so. This could be due to an interlock or some undetected abnormality. If no interlock is present, attempting to CLOSE the valve may result in a FAULT condition.

S5 INTERLOK: An interlock is present which prevents closing the valve.

S6 CLOSING: $\quad$ Status when the device has been commanded to CLOSE but the full-closed confirmation has not been received yet.

S7 OPENING: $\quad$ Status when the device has been commanded to OPEN but the full-open confirmation has not been received yet.

FAULT: The device will FAULT when the CF-OPEN or CF-CLOSD confirm is not received within a specified time after the command is issued. The FAULT can be cleared by going to OVERRIDE (Override Key) which causes the confirms to be ignored. 


\section{HNF-3569 REV 0}

\section{TEST DATA SHEET}

DEVICE: HV-EC1-1

INTERLOCKS: HV-EC1-1 Opens on interlock and can not be closed.

\begin{tabular}{|c|c|c|}
\hline PN & VALUE & DESCRIPTION \\
\hline PDI-CA1-1 & 4.5 & 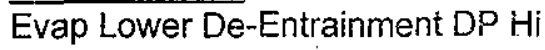 \\
\hline PDI- & 4.5 & Evap Upper De-Entrainment DP Hi \\
\hline I-CA1 & "0" & Lower De-Entrainment DP Hi \\
\hline$\$ \mathrm{G} 2$ & "0" & PB-1 Off or not Bypassed \\
\hline \$G14 & "0" & Vessel Ver \\
\hline
\end{tabular}

\section{CONFIRMS}

EPN

\begin{tabular}{|c|c|}
\hline VALUE & DESCRIPTION \\
\hline "1" & Confirm Open \\
\hline
\end{tabular}

ZS-EC1-1C "1"

Confirm Closed

OUTPUTS

DESTN VALUE DESCRIPTION

?OUTO NO Close Valve

$M I$ Verify that command 0 closes valve.

$M T$ Verify that command 1 opens valve.

MT Verify that command 2 resets the CHGSTATE status.

TESTED BY $m$ Jeate

DATE $12 / 18 / 98$ 


\section{MASTER DEVICE OV2M1SO0N}

DEV(S): HV-SUMP-1

DRAWING: $\quad$ H-2-99949 SHT 16

DESCRIPTION: This master device controls a valve with both full-open and full-closed limit switch confirmation.

COMMANDS:

CO CLOSE: $\quad$ Closes the valve.

C1 OPEN: $\quad$ Opens the valve.

AUTO/MAN: $\quad$ AUTO locks out all commands. The device should always be in MANUAL.

INTERLOCKS: This master device has no interlocks.

OVERRIDE: $\quad$ OVERRIDE (Override Key) causes the confirms to be ignored and will therefore clear the FAULT condition if it is present.

STATUSES:

SO CF-CLOSD: Closed as confirmed by the full-closed limit switch.

S1 CF-OPEN: Open as confirmed by the full-open limit switch.

S6 CLOSING: $\quad$ Status when the device has been commanded to CLOSE but the full-closed confirmation has not been received yet.

S7 OPENING: $\quad$ Status when the device has been commanded to OPEN but the full-open confirmation has not been received yet.

FAULT: The device will FAULT when the CF-OPEN or CF-CLOSD confirm is not received within a specified time after the command is issued. The FAULT can be cleared by going to OVERRIDE. When in OVERRIDE the confirms are ignored. 


\section{TEST DATA SHEET}

DEVICE: HV-SUMP-1

CONFIRMS

EPN VALUE DESCRIPTION

ZS-SUMP1C "1" $\quad$ Confirm Closed

ZS-SUMP1N "1" Confirm Open

OUTPUTS

DESTN VALUE DESCRIPTION

?OUT1 NO Opens valve

$M T$ Verify that command 0 closes valve.

MI Verify that command 1 opens valve.

TESted By Majeate DATE $12 / 19 / 98$ 


\section{MASTER DEVICE 0V2M1S44S}

DEV(S): HV-EA1-2 HV-RC1-3 HV-RC3-3

DRAWING: $\mathrm{H}-2-99949$ SHTS 17, 18

DESCRIPTION: This master device controls a two position valve with limit switch confirmation for both positions (DIVERT and NORMAL). On interlock occurrence, this valve will go to the Divert position (faildivert).

COMMANDS: CO DIVERT:

C1 NORMAL: Commands the valve to go to the NORMAL position provided there is no interlock.

C2 CS-RESET: Resets the change-of-state status (CHGSTATE) and causes the DIVERT command to follow. If this status is alarmed, it will clear the alarm.

AUTO/MAN: $\quad$ AUTO locks out all commands. The device should always be in MANUAL.

INTERLOCKS: This master device has up to four interlocks any one of which will cause the valve to go to DIVERT when activated. Interlocks are also hardwired.

OVERRIDE: OVERRIDE (Override Key) causes the confirms to be ignored and will therefore clear the FAULT condition if it is present.

STATUSES:

SO CF-DVRT: In DIVERT position as confirmed by the limit switch.

S1 CF-NORM: In NORMAL position as confirmed by the limit switch.

S2 CS-RESET: Temporary status during resetting of the CHGSTATE status.

S4 CHGSTATE: The valve went to DIVERT position as determined by the limit switch without being commanded to do so. This could be due to an interlock or some undetected abnormality. If no interlock is present, attempting to change the valve to NORMAL may result in a FAULT. condition.

S5 INTERLOK: $\quad$ An interlock is present which forces the valve to DIVERT.

S6 TRVLNGTD: Status when the device has been commanded to DIVERT but the limit switch confirmation has not been received yet.

S7 TRVLNGTN: Status when the device has been commanded to NORMAL but the limit switch confirmation has not been received yet.

FAULT: The device will FAULT when the NORMAL or DIVERT confirm is not received within a specified time after the command is issued. The FAULT can be cleared by going to OVERRIDE (Override Key). When in OVERRIDE confirms are ignored. 


\section{TEST DATA SHEET}

DEVICE: HV-EA1-2, HV-RC1-3, or HV-RC3-3

INTERLOCKS: HV-EA1-2 goes to the Divert position on interlock.

\begin{tabular}{|c|c|c|c|}
\hline EPN & VALUE & DESCRIPTION & FOR DEVICES \\
\hline$\overline{R !-R C 1-1}$ & $\overline{80}$ & Steam Condensate Rad $\mathrm{Hi}$ & $\overline{H V-E A 1-2, ~ H V-R C 1-3}$ \\
\hline Rl-EA1-1 & 750 & Steam Condensate Line Rad Hi & HV-EA1-2 \\
\hline RSH-RC1-1 & "0" & Steam Condensate Rad $\mathrm{Hi}$ & HV-EA1-2, HV-RC1-3 \\
\hline RSH-EA1-1 & "O" & Steam Condensate Line Rad Hi & HV-EA1-2 \\
\hline RI-RC & 45 & Process Condensate Rad Hi & HV-RC3-3 \\
\hline RSH-RC3-1 & "0" & Process Condensate Rad Hi & HV-RC3-3 \\
\hline
\end{tabular}

CONFIRMS

\begin{tabular}{|c|c|c|}
\hline EPN & VALUE & DESCRIPTION \\
\hline$\overline{Z S-E A 1-2 D}$ & "1" & Confirm Divert \\
\hline ZS-EA12NM & "1" & Confirm Normal \\
\hline ZS-RC1-3D & "1" & Confirm Divert \\
\hline ZS-RC13NM & "1" & Confirm Norma! \\
\hline ZS-RC3-3D & "1" & Confirm Divert. \\
\hline ZS-RC33NM & "1" & Confirm Normal \\
\hline \multicolumn{3}{|l|}{ OUTPUTS } \\
\hline DESTN & VALUE & DESCRIPTION \\
\hline ?OUT1 & $\overline{\mathrm{NO}}$ & $\overline{\text { Mov }}$ \\
\hline
\end{tabular}

$M T$ Verify that command 0 positions the valve to divert.

$M T$ Verify that command 1 positions the valve to normal.

$M \nabla$ Verify that interlock diverts the valve.

MT Verify that command 2 resets the CHGSTATE status.

\section{FOR DEVICES}

\section{HV-EA1-2}

HV-EA1-2

HV-RC1-3

HV-RC1-3

HV-RC3-3

HV-RC3-3

TESTED BY

m. Serts

DATE $12 / 18 / 98$ 
HNF-3569 REV 0

\section{MASTER DEVICE OXALMSUMP}

DEV(S): P-207A-S

DRAWING: $\mathrm{H}-2-99949$ SHT 23

DESCRIPTION: This device is used to provide an alarm if the 207-A Building sump level is high and the sump pump does not turn on.

COMMANDS:

CO RES OFF: Command issued by the device after SA-RESET. Not used by the operator.

C1: $\quad$ This is a legal command, but does not affect the device.

C2 SA-RESET: Resets the sump alarm and is followed by the RES OFF command.

AUTO/MAN: $\quad$ AUTO locks out all commands. The device should always be in MANUAL.

INTERLOCKS: This device has no interlocks.

OVERRIDE: $\quad$ Not used and has no effect on the device.

STATUSES:

SO NORMAL: Indicates that there is no alarm condition associated with the sump pump.

S2 SA-RESET: Temporary status during resetting of the SUMP ALM.

S5 HI\&P OFF: Status indicating that the sump level is high and the sump pump is not operating. The high sump level signal is delayed for 10 seconds before the alarm is generated to allow the pump to come on.

S6 SUMP ALM: Indicates the alarm status for the above condition.

FAULT: Not used on this device. 


\section{HNF-3569 REV 0}

\section{TEST DATA SHEET}

DEVICE: P-207A-S

OTHER

$\frac{\text { EPN }}{\text { LSH-P-1 }} \quad$ VALUE $\quad \frac{\text { DESCRIPTION }}{207-A \text { Building Sump Level Hi }}$

YS-P1-1 "O" Pump 207-A-P1 Not Running

OTHER TESTS OR EXPLANATION:

The SUMP ALM status ( $\$ S 6$ ) is a non-critical alarm (yellow). It clears after the SA-RESET command is issued.

InT Verify the sump alarm and reset.

TESTED BY MVyatí DATE $12 / 19 / 98$ 


\section{MASTER DEVICE OXBASPUMP}

DEV(S): $\quad 207-A-P 3$

DRAWING: $\mathrm{H}-2-99949$ SHTS 27 and 30

DESCRIPTION: Controls the operation of a motor with both current and contact confirm.

COMMANDS:

COSTOP:

Stops the motor.

C1 START: $\quad$ Starts the motor provided there is no interlock.

C2 SD-RESET: Resets the SHUTDOWN status and causes the STOP command to follow. If this status is alarmed, it will clear the alarm.

AUTOIMAN: $\quad$ Auto locks out all commands. Device should always be in Manual.

INTERLOCKS: This master device has interlocks that are hardwired and are monitored by YSPCP2(SCP3)-IL. In addition, an interlock occurs when any one of the basin levels is low and the associated drain valve is open. This condition is delayed by one minute to allow time for the valves to close.

OVERRIDE: OVERRIDE (Override Key) causes the confirms to be ignored and will therefore clear the FAULT condition if it is present.

STATUSES:

SO CF-OFF:

S1 CF-ON:

S2 SD-RESET: Temporary status during resetting of the SHUTDOWN status.

S4 SHUTDOWN: The motor has stopped as confirmed by the contactor or motor current without being commanded to stop. This could be due to an interlock (as indicated by the INTERLOK status) or due to some abnormal condition not monitored by the device. If no interlock is present after SHUTDOWN, attempting to restart the motor may result in a FAULT condition.

S5 INTERLOK: Indicates an interlock condition is present.

S6 STOPPING: The motor has been commanded to stop but the contact and motor current confirm are still present.

S7 STARTING: The motor has been commanded to start but the contact and current confirms have not been received yet.

FAULT: The device will fault when it does not start or stop within the allowable time period after the associated command is issued. The FAULT condition can be cleared by going to OVERRIDE (Override Key). 
DEVICE: 207-A-P3

INTERLOCKS: 207-A-P3 Stops and will not start on interlock.

\begin{tabular}{|c|c|c|}
\hline EPN & VALUE & DESCRIPTION \\
\hline$\overline{Z S-S C-1 D C}$ & "0" & $\overline{\text { Valve HV-SC-1B Open }}$ \\
\hline LSL-SC-1 & "0" & Basin \#1 Level Lo \\
\hline ZS-SC-2DC & "0" & Valve HV-SC-2B Open \\
\hline LSL-SC-2 & "0" & Basin \#2 Level Lo \\
\hline ZS-SC-3DC & "0" & Valve HV-SC-3B Open \\
\hline LSL-SC-3 & "0" & Basin \#3 Level Lo \\
\hline YS-SCP3IL & "0" & Hardwired Interlock Activ \\
\hline
\end{tabular}

\section{CONFIRMS}

\begin{tabular}{|c|c|c|}
\hline EPN & $\underline{\text { VALUE }}$ & DESCRIPTION \\
\hline $\begin{array}{l}11-S C-P 3 \\
\text { YS-SC-P3 }\end{array}$ & & nt Confirm \\
\hline
\end{tabular}

OUTPUTS

DESTN VALUE DESCRIPTION

?OUT1 NO Motor Start(1)/Stop(0)

FAULT OVERRIDE $N A$ TEST EXCEPTION \# 3

$M \bigvee$ Verify that the interlock stops motor and prevents starting of motor.

MT Verify that command 0 turns off the motor.

$M T$ Verify that command 1 turns on the motor.

$M Y$ Verify that command 2 resets the shutdown of the motor following interlock.

TESTED ву MP Qeat DATE $12 / 19 / 98$ 


\section{HNF-3569 REV 0}

\section{MASTER DEVICE OXBOTDUMP}

$\operatorname{DEV}(\mathbf{S}): \quad$ BOT-DUMP

DRAWING: $\mathrm{H}-2-99949 \mathrm{SHT} 15$

DESCRIPTION: This device is used to control the dumping of the pot as well as flushing the pot and dump lines. When bypass goes to active (from PB1-BYPAS), the valves will be placed in the BLOCK position. On loss of bypass, a 30 second POT FLUSH will occur and then the valves will be placed in the DUMP position. The operator may select the BLOCK, DUMP, or LINEFLSH positions whenever the bypass is active. On selection of POT FLUSH, the pot is flushed for 30 seconds and the valves revert to the DUMP position.

\section{COMMANDS:}

C0 BLOCK: $\quad$ Valves HV-CA1-7, 8, and 9 are placed in the BLOCK position (7 and 9 closed, 8 open).

C1 DUMP: $\quad$ Valves HV-CA1-7, 8 and 9 are placed in the DUMP position ( 7 and 9 open, 8 closed).

C2 POT FLSH: Valves HV-CA1-7, 8, and 9 are placed in the POT FLUSH position (7 and 8 open, 9 closed).

C3 LINEFLSH: Valves HV-CA1-7, 8, and 9. are placed in the LINEFLSH position ( 8 and 9 open, 7 closed).

AUTO/MAN: Device should always be in MANUAL.

INTERLOCKS: No interlocks on this device.

OVERRIDE: $\quad$ Not used on this device.

STATUSES:

SO BLOCK: Valves HV-CA1-7, 8, and 9 are in the BLOCK position (7 and 9 closed, 8 open).

S1 DUMP: $\quad$ Valves HV-CA1-7, 8 and 9 are in the DUMP position ( 7 and 9 open, 8 closed).

S2 POT FLSH: Valves HV-CA1-7, 8 , and 9 are in the POT FLUSH position (7 and 8 open, 9 closed).

S3 LINEFLSH: Valves HV-CA1-7, 8, and 9 are in the DUMP FLUSH position ( 8 and 9 open, 7 closed).

FAULT: Not used by this device. 


\section{HNF-3569 REV 0}

\section{TEST DATA SHEET}

DEVICE: BOT-DUMP

OTHER

DESTN

$\$$ G2

VALUE DESCRIPTION

"0" PB-1 off or not in Bypass

OUTPUTS

DESTN

VALUE

?OUT7

NO

NO

?OUT9

NO

DESCRIPTION

Close (1) HV-CA1-7

Open (1) HV-CA1-8

Close (1) HV-CA1-9

$M r$ Verify that when PB1 is running that the valves are positioned to BLOCK.

'MT Verify that command 0 or PB1-BYPAS "BYPASS" positions the valves to BLOCK.

$M T$ Verify that command 1 positions the valves to DUMP.

MT Verify that command 2 positions the valves to POTFLSH.

MT Verify that command 3 positions the valves to LINEFLSH.

tested by M Deat DATE $12 / 19 / 98$ 


\section{HNF-3569 REV 0}

\section{MASTER DEVICE OXEA1ILK2}

$\operatorname{DEV}(\mathrm{S}): \quad$ EA1-INLK2

DRAWING: $\quad \mathrm{H}-2-99949$ SHT 12

DESCRIPTION: This device is used to bypass the Reboiler low pressure and low steam flow interlocks to the Reboiler steam valve (FV-EA1-1).

COMMANDS:

CONOBYPASS: Turns off the bypass condition.

C1 BYPASS: $\quad$ Turns on the bypass condition.

AUTO/MAN: Auto locks out all commands: Device should always be in Manual.

INTERLOCKS: This device has two interlocks.

OVERRIDE: OVERRIDE (Override Key) has no effect on this master device.

STATUSES:

SO NOBYPASS: Not in bypass.

S1 BYPASS: $\quad$ Bypass condition is on.

S5 INTERLOK: Interlocks are present.

FAULT: Not used on this device. 
HNF-3569 REV 0

TEST DATA SHEET

DEVICE: $\quad$ EA1-INLK2

INTERLOCKS

EP VALUE DESCRIPTION

Pl-EA1-1 $17.2 \quad$ Reboiled Pressure Low

FIC-EA1-1 $3000 \quad$ Reboiled Steam Flow Low

OUTPUTS

$\frac{\text { DESTN }}{\$ G 12} \quad \frac{\text { VALUE }}{0 / 1} \quad \frac{\text { DESCRIPTION }}{\text { Passes Interlock Condition to FV-EA1-1 }}$

$m$ Verify that the interlocks, such as low steam flow, are passed to FV-EA1-1 when not bypassed. In this case, \$G12 should be zero.

$M T$ Verify that command 0 turns off the bypass condition.

MT Verify that command 1 turns on the bypass condition $(\$ G 12=1)$.

TESTED Br $m$. Eats DATE $12 / 19 / 98$

48 


\section{MASTER DEVICE 0XEC2S3D1}

$\operatorname{DEV}(\mathrm{S}): \quad$ HVEC2/3-1

DRAWING: H-2-99949 SHT 5

DESCRIPTION: This master device controls a valve with both full-open and full-closed limit switch confirmation. On interlock occurrence, this valve will close (fail-close).

COMMANDS:

CO CLOSE:

C1 OPEN: $\quad$ Opens the valve provided no interlock is present.

C2 CS-RESET: Resets the change-of-state status (CHGSTATE) and causes the CLOSE command to follow. If this status is alarmed; it will clear the alarm.

AUTOIMAN: $\quad$ AUTO locks out all commands. The device should always be in MANUAL.

INTERLOCKS: This device has two interlocks, one of which is delayed by 255 seconds. This delayed interlock will close HVEC2/3-1 if valve HV-EC1-1 is in the "not closed" state for 255 seconds. The other interlock is passed from EX-C-1 via Global Bit G14. In addition there are hardwired interlocks.

OVERRIDE: OVERRIDE (Override Key) causes the confirms to be ignored and will therefore clear the FAULT condition if it is present.

STATUSES:

SO CF-CLOSD: Closed as confirmed by the full-closed limit switch.

S1 CF-OPEN: Open as confirmed by the full-open limit switch.

S2 CS-RESET: Temporary status during resetting of the CHGSTATE status.

S4 CHGSTATE: The valve closed as determined by the CF-CLOSD confirm without being commanded to do so. This could be due to an interlock or some undetected abnormality. If no interlock is present, attempting to OPEN the valve may result in a FAULT condition.

S5 INTERLOK: An interlock is present which prevents opening the valve.

S6 CLOSING: $\quad$ Status when the device has been commanded to CLOSE but the full-closed confirmation has not been received yet.

S7 OPENING: $\quad$ Status when the device has been commanded to OPEN but the full-open confirmation has not been received yet.

FAULT: The device will FAULT when the CF-OPEN or CF-CLOSD confirm is not received within a specified time after the command is issued. The FAULT can be cleared by going to OVERRIDE. When in OVERRIDE the confirms are ignored. 


\section{TEST DATA SHEET}

DEVICE: HVEC2/3-1

INTERLOCKS: HVEC2/3 Closed on interlock.

EPN VALUE DESCRIPTION.

ZS-EC1-1C "0" Valve HV-EC1-1 not closed

\$G14 "0" Vessel Vent Interlocks

CONFIRMS

EPN VALUE DESCRIPTION

ZSEC2/31C "1" Confirm Closed

ZSEC2/31N "1" Confirm Open

OUTPUTS

$\frac{\text { DESTN }}{\text { ?OUT1 }} \frac{\text { VALUE }}{\text { NO }} \quad \frac{\text { DESCRIPTION }}{\text { Opens valve }}$

$M T$ Verify that command 0 closes the valve.

$M T$ Verify that command 1 opens the valve.

$M T$ Verify that interlock closes the valve.

$M J$ Verify that command 2 resets the CHGSTATE status.

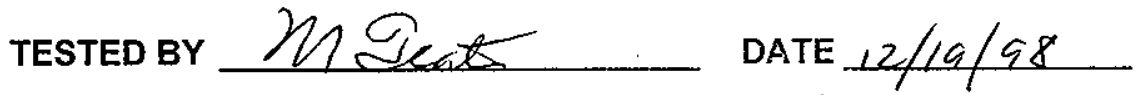




\section{MASTER DEVICE OXEXHDCD1}

$\operatorname{DEV}(\mathrm{S}): \quad$ EX-C-1

DRAWING: $\quad \mathrm{H}-2-99949$ SHT 24

DESCRIPTION: Controls the operation of a motor with contact confirm. Two pulsed outputs are used - one for START and one for STOP. This master device is used for motors that have a remote manual start/stop station and a Remote/Local switch.

COMMANDS:

CO STOP: $\quad$ Stops the motor.

C1 START: $\quad$ Starts the motor provided there is no interlock.

C2 SD-RESET: Resets the SHUTDOWN status and causes the STOP command to follow. If this status is alarmed, it will clear the alarm.

AUTO/MAN/LOC: Auto locks out all commands. Device should always be in Manual. When the Remote/Local switch is in the Local position, the motor can only be started from the local start/stop station.

INTERLOCKS: This master device has one interlock (Global bit 19 from VCA1-INLK). When active, the interlock will stop the motor and cause the stop output to remain open continuously thereby preventing manual starting of the motor.

OVERRIDE: OVERRIDE (Override Key) causes the confirms to be ignored and will therefore clear the FAULT condition if it is present.

STATUSES:

SO CF-OFF:

Not running as confirmed by the motor contactor or current.

S1 CF-ON: $\quad$ Running as confirmed by the motor contactor and current.

S2 SD-RESET: Temporary status during resetting of the SHUTDOWN status.

S4 SHUTDOWN: The motor has stopped as confirmed by the contactor without being commanded to stop. This could be due to an interlock (as indicated by the INTERLOK status) or due to some abnormal condition not monitored by the device (remote stop). If no interlock is present after SHUTDOWN, attempting to restart the motor may result in a FAULT condition.

S5 INTERLOK: Indicates an interlock condition is present.

S6 STOPPING: The motor has been commanded to stop but the contact and current are still present.

S7 STARTING: The motor has been commanded to start but the contact and current confirm have not been received yet.

FAULT: The device will fault when it does not start or stop within the allowable time period after the associated command is issued. The FAULT condition can be cleared by going to OVERRIDE (Override Key). 
HNF-3569 REV 0

\section{MASTER DEVICE OXEXC1ILK}

DEV(S): EXC1-INLK

DRAWING: $\mathrm{H}-2-99949$ SHT 24

DESCRIPTION: This device is used to pass the Vessel Vent interlocks to the exhauster control device EXC-1.

COMMANDS: None

AUTO/MAN: $\quad$ No effect.

INTERLOCKS: This device has six interlocks.

OVERRIDE: OVERRIDE (Override Key) has no effect on this master device.

STATUSES:

SO NORMAL: No interlock is activated.

S5 INTERLOK: One or more of the six interlocks is activated.

FAULT: Not used on this device. 


\section{HNF-3569 REV 0}

\section{TEST DATA SHEET}

DEVICE: $\quad$ EX-C-1

INTERLOCKS: EX-C-1 Stops and will not start on interlock.

$\frac{\text { DESTN }}{\text { \$G19 }} \quad \frac{\text { VALUE }}{\text { "0" }} \quad \frac{\text { DESCRIPTION }}{\text { Interlocks Passed from EXC1-INLK. }}$

\section{CONFIRMS}

EPN

VALUE DESCRIPTION

II-EXC-1

YS-EXC-1 "1"

Current Confirm

Contact Confirm

\section{OTHER}

EPN

VALUE DESCRIPTION

YS-EXC3RL

"0" EX-C-1 in Local Control Mode

OUTPUTS

DESTN VALUE DESCRIPTION

?OUT1 NO Start Pulse

?OUTO NC Stop Pulse

$M T$ Verify that the interlock stops motor and prevents starting of motor.

$M \pi$ Verify that command 0 turns off the motor.

Verify that command 1 turns on the motor.

$M \bigvee$ Verify that command 2 resets the shutdown of the motor following interlock.

$M T$ Verify that the motor can not be started from the keyboard when in LOCAL.

TESTED BY $2 M$ DATE $12 / 19 / 98$ 
HNF-3569 REV 0

TEST DATA SHEET

DEVICE: EXC1-INLK

INTERLOCKS

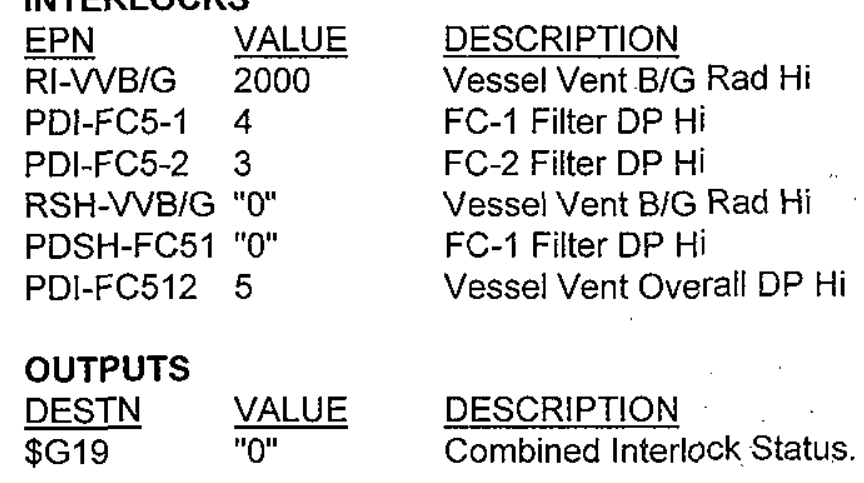

MT Verify that INTERLOCK status is back-lit when interlock is tripped.

TESTED BY Ma ta DATE _i2/19/98

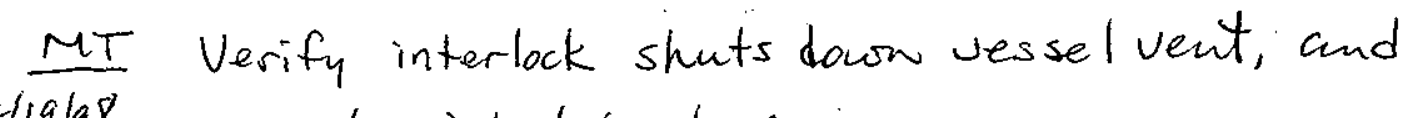
$12 / 19198$ cascades interlock to:

$$
\begin{aligned}
& \text { P-AW-1O2 } \\
& \text { VCAI-INLK } \\
& \text { FU-EA1-1 } \\
& \text { HU-ECI-1 } \\
& \text { HUECZ/3-1 }
\end{aligned}
$$

54 


\section{MASTER DEVICE OXFVEA1D1}

$\operatorname{DEV}(\mathbf{S}): \quad$ FV-EA1-1

DRAWING: $\mathrm{H}-2-99949$ SHT 12

DESCRIPTION: This device controls the operation of the air/steam to the Reboiler. A steam permissive signal is sent to the steam controller PIC-EA1-1 whenever the AIR OFF command is active and reboiler pressure drops below the lower limit as determined by PI-EA1-1. The permissive is removed whenever the steam valve closes or when the AIR OFF is activated and the reboiler pressure is high.

\section{COMMANDS:}

C0 AIR OFF: $\quad$ Causes the air valve to turn off and permits the steam valve to be turned on (opens solenoid valve between controller PIC-EA1-1 and steam valve FV-EA1-1) provided there are no interlocks.

C1 AIR ON: $\quad$ Opens air valve HV-EA1-3 and closes steam valve PV-EA1-1.

AUTO: $\quad$ Auto locks out all commands. Device should always be in Manual.

INTERLOCKS: This device has numerous software and hardwired interlocks. On occurrence of an interlock, the air is turned on and the steam is turned off. Some of the interlocks can be bypassed using Devices EA1-INLK1 and EA1-INLK2. See descriptions of these devices for details of their operation.

OVERRIDE: $\quad$ Not used on this device.

STATUSES:

So AIR OFF: $\quad$ Air off. Steam can be turned on with a software permissive to the steam controller PICEA1-1.

S1 AIR ON: $\quad$ Air on and steam off.

S2 STM PRMI: Air off and software permissive to steam controller (Reboiler pressure no longer high).

S5 INTERLOK: An interlock is present.

FAULT: Not used on this device. 


\section{HNF-3569 REV 0}

\section{TEST DATA SHEET}

\section{DEVICE: FV-EA1-1}

INTERLOCKS: Will go to AIR ON status when any one or more of the interlocks is present.

\begin{tabular}{|c|c|}
\hline PN & VALUE \\
\hline TI-DSH-3 & $\overline{250}$ \\
\hline RI-CA1-1 & 8000 \\
\hline PI-CA1-11 & 20 \\
\hline RI-RC1-1 & 80 \\
\hline RI-EA1-1 & 750 \\
\hline YS-PB1-1 & "0" \\
\hline RSH-CA1-1 & "0" \\
\hline PSH-CA111 & "O" \\
\hline RSH-RC1-1 & "0" \\
\hline RSH-EA1-1 & "0" \\
\hline TSH-DSH-3 & "0" \\
\hline ZS-EC1-C & "0" \\
\hline$\$ \mathrm{G} 7$ & "0" \\
\hline \$G12 & "0" \\
\hline$\$ G 14$ & "0 \\
\hline
\end{tabular}

\section{DESCRIPTION}

Reboiler Steam Inlet Temp Hi

PC Line Rad Hi

Evaporator Pressure Hi

Steam Condensate $\mathrm{Rad} \mathrm{Hi}$

Steam Condensate Line Rad Hi

PB-1 off

PC Line Rad Hi

Evaporator Pressure $\mathrm{Hi}$

Steam Condensate Rad $\mathrm{Hi}$

Steam Condensate Line Rad Hi

Desuperheater Outlet Temp Hi-Hi

Vacuum Breaker Valve Not Closed

Interlocks from EA1-INLK1

Interlocks from EA1-INLK2

interlocks from Vessel Vent

\section{OTHER}

EPN VALUE

PI-EA1-1 29.7

ZS-EA1-C "1"

DESCRIPTION

Reboiler Pressure Hi

Steam Valve FV-EA1-1 Closed

OUTPUTS

DESTN

?OUTO

VALUE

NO

"1"

DESCRIPTION

Close Air Valve and Open Steam Valve

Steam Permissive to FIC-EA1-1

MT Verify that command 0 turns air off.

MT Verify that command 1 turns air on.

$m I$ Verify that the Steam Permissive is " 0 " when in AIR OFF status and Reboiler Pressure is high.

MT Verify that the Steam Permissive is " 1 " when in AIR OFF status and Reboiler Pressure returns to normal (not high).

TESTED BY M. Q Decto DATE $12 / 19 / 98$ 


\section{MASTER DEVICE OXGBITDS1}

DEV(S): ' GBITO-0/1

DRAWING: $\mathrm{H}-2-99949 \mathrm{SHT} 4$

DESCRIPTION: This device provides a constant logic $0(\$ G 0)$ and a constant logic 1 (\$G1) for use in PCM0 devices ( 1 XGBITOS1 does the same for PCM 1). They are typically used to provide a fixed input to an unused logic gate. In some cases this allows the use of the same master device for more than one device.

COMMANDS:

CO NORMAL: The device is always forced to this command.

AUTO/MAN: $\quad$ Has no affect on the operation of this device.

INTERLOCKS: This device has no interlocks.

OVERRIDE: $\quad$ Not used on this device.

STATUSES: None

FAULT: Not used on this master device.

\section{TEST DATA SHEET}

DEVICE: GBIT0-0/1

OUTPUTS

$\frac{\text { DESTN }}{\$ G 0} \quad \frac{\text { DALUE }}{\text { "0" }} \quad \frac{\text { DESCRIPTION }}{\text { Should always be logic "0" }}$

\$G1 "1" Should always be logic " 1 "

\section{OTHER EXPLANATION:}

These can be verified by looking on the Loop. Maintenance Display for the value of $\$ T 1$ which is equal to $\$ \mathrm{G} 1$ and for the value of $\$ \mathrm{~T} 2$ which is equal to the value of $\$ \mathrm{G} 0$.

$M$ Verify the values of $\$ \mathrm{G} 0$ and $\$ \mathrm{G} 1$ are correct.

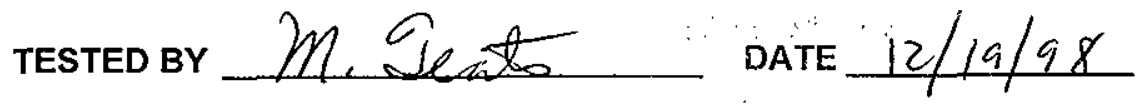




\section{MASTER DEVICE OXHVCA1D1}

$\operatorname{DEV}(\mathrm{S}): \quad H V-C A 1-1$

DRAWING: $\quad \mathrm{H}-2-99949 \mathrm{SHT} 6$

DESCRIPTION: This master device controls a valve with both full-open and full-closed limit switch confirmation. On interlock occurrence, this valve will close (fail-close).

COMMANDS:

CO CLOSE:

C1 OPEN:

C2 CS-RESET:

AUTO/MAN:

INTERLOCKS:

OVERRIDE:

STATUSES:

SO CF-CLOSD:

S1 CF-OPEN:

S6 CLOSING:

S7 OPENING:

S5 INTERLOK:

S4 CHGSTATE:
Closes the valve.

Opens the valve provided no interlock is present.

Resets the change-of-state status (CHGSTATE) and causes the CLOSE command to follow. If this status is alarmed, it will clear the alarm.

AUTO locks out all commands. The device should always be in MANUAL.

This master device has three interlocks that will cause the valve to close when activated. One of the interlocks (P-AW-102 shutdown) causes HV-CA1-1 to close on shutdown of P-AW-102, however, HV-CA1-1 can be opened again. Device HV-CA1-1 is linked to Device VCA1-INLK via a global bit (G10). Device VCA1-INLK has multiple interlock inputs that are passed to HV-CA1-1 through this global bit. See the description for VCA1-INLK.

OVERRIDE (Override Key) causes the confirms to be ignored and will therefore clear the FAULT condition if it is present.

Closed as confirmed by the full-closed limit switch.

Open as confirmed by the full-open limit switch.

Status when the device has been commanded to CLOSE but the full-closed confirmation has not been received yet.

Status when the device has been commanded to OPEN but the full-open confirmation has not been received yet.

An interlock is present which prevents opening the valve.

The valve closed as determined by the CF-CLOSD confirm without being commanded to do so. This could be due to an interlock or some undetected abnormality. If no interlock is present, attempting to OPEN the valve may result in a FAULT condition.

S2 CS-RESET: Temporary status during resetting of the CHGSTATE status.

FAULT: The device will FAULT when the CF-OPEN or CF-CLOSD confirm is not received within a specified time after the command is issued. The FAULT can be cleared by going to OVERRIDE. When in OVERRIDE the confirms are ignored. 


\section{HNF-3569 REV 0}

\section{TEST DATA SHEET}

\section{DEVICE: HV-CA1-1}

INTERLOCKS: Any one or more of the interlocks will cause HV-CA1-1 to close. Interlocks $\$$ G2 and $\$$ G10 also prevent the opening of HV-CA1-1.

\begin{tabular}{lll} 
EPN & VALUE & DESCRIPTION \\
\cline { 2 - 2 } & & Pump P-AW-102 off \\
$\$$ \$G2 & "0" & PB-1 off or not Bypassed \\
\$G10 & "0" & Combined interlocks from VCA1-INLK
\end{tabular}

\section{CONFIRMS}

EPN

DESCRIPTION

Confirm Closed

ZS-CA1-1N "1"

Confirm Open

\section{OUTPUTS}

DESTN $\quad$ VALUE DESCRIPTION

$M T$ Verify that command 0 closes the valve.

$M T$ Verify that command 1 opens the valve.

MT Verify that interlock closes the valve.

$m$ Verify that command 2 resets the CHGSTATE status.

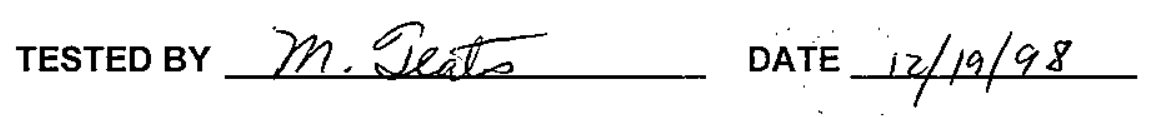




\section{HNF-3569 REV 0 \\ MASTER DEVICE OXHVCA1D5}

DEV(S): HV-CA1-5

DRAWING: $\mathrm{H}-2-99949 \mathrm{SHT} 7$

DESCRIPTION: This device controls a two-position valve with limit switch confirmation for both positions. COMMANDS:

CO NOZZLE 4: Moves the valve to the Nozzle 4 position.

C1 NOZZLE 5: $\quad$ Moves the valve to the Nozzle 5 Position.

AUTO/MAN: $\quad$ AUTO locks out all commands. The device should always be in MANUAL.

INTERLOCKS: This device has no interlocks.

OVERRIDE: OVERRIDE (Override Key) causes the confirms to be ignored and will therefore clear the FAULT condition if it is present.

\section{STATUSES:}

SO CF-NOZ 4: Valve is in the Nozzle 4 position as confirmed by the limit switch.

S1 CF-NOZ 5: Valve is in the Nozzle 5 position as confirmed by the limit switch.

S6 TRVLNGT4: Valve is traveling to Position 4.

S7 TRVLNGT5: Valve is traveling to Position 5.

FAULT: Not used on this master device. 
HNF-3569 REV 0

TEST DATA SHEET

DEVICE: HV-CA1-5

CONFIRMS

EPA VALUE DESCRIPTION

ZS-CA1-54 "1" $\quad$ Confirm Nozzle 4 Position

ZS-CA1-55 "1" Confirm Nozzle 5 Position

OUTPUTS

$\frac{\text { DESTN }}{\text { ?OUT }} \quad \frac{\text { VALUE }}{\text { NO }} \quad \frac{\text { DESCRIPTION }}{\text { Puts valve in Nozzle } 5 \text { Position }}$

MT Verify that command 0 closes the valve. (TO AW-B $P(T)$ MT 12/19/g8

$M T$ Verify that command 1 opens the valve. (TO Aw -A $P_{1 T}$ ) $m_{T} \quad 12 / 19 / 98$

TESTED By MATE DAT /19/98

61 


\section{MASTER DEVICE OXHVCA1D6}

$\operatorname{DEV}(\mathrm{S}): \quad \mathrm{HV}-\mathrm{CA} 1-6$

DRAWING: $\quad$ H-2-99949 SHT 14

DESCRIPTION: This master device controls a valve with both full-open and full-closed limit switch confirmation. In addition, the valve is opened automatically whenever the slurry flush is active (Global bit 3).

\section{COMMANDS:}

CO CLOSE: $\quad$ Closes the valve provided the slurry flush is not active.

C1 OPEN: $\quad$ Opens the valve.

AUTO/MAN: $\quad$ AUTO locks out all commands. The device should always be in MANUAL.

INTERLOCKS: This master device has no interlocks.

OVERRIDE: $\quad$ OVERRIDE (Override Key) causes the confirms to be ignored and will therefore clear the FAULT condition if it is present.

\section{STATUSES:}

SO CF-CLOSD: Closed as confirmed by the full-closed limit switch.

S1 CF-OPEN: Open as confirmed by the full-open limit switch.

S6 CLOSING: $\quad$ Status when the device has been commanded to CLOSE but the full-closed confirmation has not been received yet.

S7 OPENING: $\quad$ Status when the device has been commanded to OPEN but the full-open confirmation has not been received yet.

FAULT: The device will FAULT when the CF-OPEN or CF-CLOSD confirm is not received within a specified time after the command is issued. The FAULT can be cleared by going to OVERRIDE. When in OVERRIDE the confirms are ignored. 
DEVICE: HV-CA1-6

\section{CONFIRMS}

$\frac{\text { EPN }}{\text { ZS-CA1-6N }} \frac{\text { VALUE }}{" 1 "} \quad \frac{\text { DESCRIPTION }}{\text { Confirm Open }}$

ZS-CA1-6C "1" Confirm Closed

OUTPUTS

$\frac{\text { DESTN }}{\text { ?OUTO }} \quad \frac{\text { VALUE }}{\text { NO }} \quad \frac{\text { DESCRIPTION }}{\text { Closes valve }}$

MI Verify that command 0 closes the valve:

$M T-V e r i f y$ that command 1 opens the valve.

TESTED BY M a DATE 12/9/98 


\section{MASTER DEVICE OXJGVALVE}

$\operatorname{DEV}(\mathrm{S}): \quad J G V-S U M P$

DRAWING: H-2-99949 SHT 16

DESCRIPTION: This device is used to control a steam jet or jet gang valve.

COMMANDS:

CO STOP: Stops the jet. Always followed by 60 seconds of air blow.

C1 START: Starts the jet. Will continue until stopped.

AUTO/MAN: Auto locks out all commands. Device should always be in Manual.

INTERLOCKS: This device has no interlocks.

OVERRIDE: Not used in this device.

STATUSES:

SO OFF: $\quad$ No steam or air.

S1 ON: Jet is on (steam).

S2 AIR BLOW: Air purge for 60 seconds after turning off.

S3 ON 8MIN+: This will be the status if the jet is left $O N$ for 8.5 minutes. The jet will remain $O N$ but will indicate this status.

FAULT: Not used on this device. 


\section{HNF-3569 REV 0}

\section{TEST DATA SHEET}

DEVICE: JGV-SUMP

OUTPUTS

DESTN

VALUE

NO

DESCRIPTION

?OUTB

NO

On during Jet and $60 \mathrm{sec}$ Air Blow

On during Jet (Steam)

$M T$ Verify that command 1 starts the jet.

$N / A$ Verify that a non-critical alarm is generated if the jet is on for more than 8.5 minutes.

MT Verify that command 0 stops the jet.

TESTED BY M Geata DATE $12 / 19 / 98$ 


\section{MASTER DEVICE OXMDPC100}

DEV(S): P-C100

DRAWING: $\mathrm{H}-2-99949$ SHT 22

DESCRIPTION: Controls the operation of a motor with both current and contact confirm. This master device has up to seven interlocks.

COMMANDS:

COSTOP:

C1 START: $\quad$ Starts the motor provided there is no interlock.

C2 SD-RESET: Resets the SHUTDOWN status and causes the STOP command to follow. If this status is alarmed, it will clear the alarm.

AUTO/MAN: $\quad$ Auto locks out all commands. Device should always be in Manual.

INTERLOCKS: This master device can have up to seven interlocks. These devices all have hardwired interlocks also.

OVERRIDE: $\quad$ OVERRIDE (Override Key) causes the confirms to be ignored and will therefore clear the FAULT condition if it is present.

STATUSES:

SO CF-OFF:

Not running as confirmed by the motor contactor or the motor current.

S1 CF-ON: $\quad$ Running as confirmed by the motor contactor and the motor current.

S2 SD-RESET: Temporary status during resetting of the SHUTDOWN status.

S4 SHUTDOWN: The motor has stopped as confirmed by the contactor or motor current without being commanded to stop. This could be due to an interlock (as indicated by the INTERLOK status) or due to some abnormal condition not monitored by the device. If no interlock is present after SHUTDOWN, attempting to restart the motor may result in a FAULT condition.

S5 INTERLOK: Indicates an interlock condition is present.

S6 STOPPING: The motor has been commanded to stop but the contact and motor current confirm are still present.

S7 STARTING: The motor has been commanded to start but the contact and current confirms have not been received yet.

FAULT: The device will fault when it does not start or stop within the allowable time period after the associated command is issued. The FAULT condition can be cleared by going to OVERRIDE (Override Key). 


\section{HNF-3569 REV 0}

\section{TEST DATA SHEET}

DEVICE: P-C100

INTERLOCKS: P-C100 Stops and will not start on interlock.

\begin{tabular}{|c|c|c|}
\hline DESTN & VALUE & DESCRIPTION \\
\hline$\$ \mathrm{G} 13$ & $0 / 1$ & From PC-INLK1 interlocks \\
\hline$\$ G 20$ & $0 / 1$ & From LERFILK interlocks \\
\hline$\$$ G22 & $0 / 1$ & From PC-INLK2 interlocks \\
\hline
\end{tabular}

CONFIRMS

\begin{tabular}{|c|c|c|}
\hline EPN & VALUE & CRIPTION \\
\hline $\begin{array}{l}\text { II-P-C100 } \\
\text { YS-P-C100 }\end{array}$ & & $\begin{array}{l}\text { Motor Current Confirm } \\
\text { Motor Contact Confirm }\end{array}$ \\
\hline
\end{tabular}

OUTPUTS

DESTN VALUE DESCRIPTION

- ?OUT1 NO Motor Start(1)/Stop(0)

FAULT OVERRIDE NAA

TEST EXCEPTINN 3

$M T$ Verify that the interlock stops motor and prevents starting of motor.

$M T$ Verify that command 0 turns off the motor:

$M T$ Verify that command 1 turns on the motor. to propen destisation (LERF), mr

$M V$ Verify that command 2 resets the shutdown of the motor following interlock.

tested вy M Q ieat DATE $12 / 19 / 98$

MI Verify command starts to divert when HVRC33 diverted. MT Verify pump will not start to wrong destination.

$12 / 19 / 88$ $m$, 


\section{MASTER DEVICE OXMDPC106}

DEV(S): P-C106

DRAWING: $\quad$ H-2-99949 SHT 55

DESCRIPTION: Controls the operation of a motor with both current and contact confirm. This master device has four interlocks.

COMMANDS:

CO STOP:

C1 START:

C2 SD-RESET:

AUTOIMAN:

INTERLOCKS:

OVERRIDE:

STATUSES:

SO CF-OFF:

S1 CF-ON:

S2 SD-RESET: Temporary status during resetting of the SHUTDOWN status.

S4 SHUTDOWN: The motor has stopped as confirmed by the contactor or motor current without being commanded to stop. This could be due to an interlock (as indicated by the INTERLOK status) or due to some abnormal condition not monitored by the device. If no interlock is present after SHUTDOWN, attempting to restart the motor may result in a FAULT condition.

S5 INTERLOK: Indicates an interlock condition is present.

S6 STOPPING: The motor has been commanded to stop but the contact and motor current confirm are still present.

S7 STARTING: The motor has been commanded to start but the contact and current confirms have not been received yet.

FAULT: The device will fault when it does not start or stop within the allowable time period after the associated command is issued. The FAULT condition can be cleared by going to OVERRIDE (Override Key). 


\section{TEST DATA SHEET}

DEVICE: P-C106

INTERLOCKS: P-C106 Stops and will not start on interlock.

EPN VALUE DESCRIPTION

WFIC-C100 $27 \quad$ Tank C-100 weight factor Lo

PDI-FC4/5 $20 \quad$ F-C-4/5 filter differential pressure $\mathrm{Hi}$

RSH-RC3-1 "O" Process condensate radiation $\mathrm{Hi}$

RSH-CA1-1 " 0 " Process condensate line radiation $\mathrm{Hi}$

\section{CONFIRMS}

EPN VALUE DESCRIPTION

II-P-C106 Motor Current Confirm.

YS-P-C106 "1" Motor Contact Confirm

OUTPUTS

DESTN VALUE DESCRIPTION

?OUT0 NO Motor Start(1)/Stop(0)

FAULT OVERRIDE N/A TEST EXCEPTION \#3

$M$ Verify that the interlock stops motor and prevents starting of motor.

$M T$ Verify that command 0 turns off the motor.

M $T$ Verify that command 1 turns on the motor.

$M T$ Verify that command 2 resets the shutdown of the motor following interlock.

TESTED BY M Seate DATE $12 / 19 / 98$ 


\section{MASTER DEVICE OXPADSPRY}

DEV(S): HV-PDSPRY

DRAWING: $\mathrm{H}-2-99949$ SHT 15

DESCRIPTION: This device is used to control the sequencing of the pad spray valves. When the device is started the valves will sequence, opening for 15 seconds each. The sequence order is $10,11,12,13$, and back to 10 .

COMMANDS:

CO STOP: $\quad$ Closes all pad spray valves.

C1 START10: Initiates pad spray sequence with valve CA1-10.

C2 START11: Initiates pad spray sequence with valve CA1-11.

C3 START12: Initiates pad spray sequence with valve CA1-12.

C4 START13: Initiates pad spray sequence with valve CA1-13.

AUTO/MAN: $\quad$ Auto locks out all commands. Device should always be in Manual.

INTERLOCKS: No interlocks on this device.

OVERRIDE: Not used. Has no effect on the device.

STATUSES:

SO STOPPED: $\quad$ No pad spray valves open.

S1 CA1-10: Valve CA1-10 open.

S2 CA1-11: Valve CA1-11 open.

S3 CA1-12: Valve CA1-12 open.

S4 CA1-13: Valve CA1-13 open.

FAULT: Not used on this device. 
HNF-3569 REV 0

TEST DATA SHEET

DEVICE: HV-PDSPRY

OUTPUTS

DESTN

?OUT10

?OUT11

?OUT12

?OUT13

VALUE
NO
NO
NO
NO

DESCRIPTION

Open Valve CA $1-10$

Open Valve CA 1-11

Open Valve CA 1-12

Open Valve CA $1-13$

MT Verify that command 1 starts the sequence.

$M T$ Verify that sequences cycle through all valves.

$M T$ Verify that command 0 stops the sequence.

TESTED BY $m$ ate so

DATE $12 / 19 / 98^{\circ}$

71 


\section{MASTER DEVICE OXPB1BYPA}

DEV(S): PB1-BYPAS

DRAWING: $\mathrm{H}-2-99949 \mathrm{SHT} 8$

DESCRIPTION: This device is used to bypass the PB-1 shutdown status. Whenever PB-1 is on (as determined by the contactor YS-PB-1), this device will be in PB1 ON status and the interlock to other devices will be inhibited. Whenever PB-1.shuts off, this device will go to TIME BYP status and will continue to inhibit the interlock until Timer KY-PB1-1 times out. After KY-PB1-1 times out, this device will go to BYP OFF and the interlock will be activated. The interlocks can be inhibited by going to BYP ON (Command \#1). The device will remain in BYP ON until turned off (Command \#0) or until PB-1 starts. When in BYP OFF the device activates interlocks to:

1. Open the vacuum breaker valve HV-EC1-1,

2. Close feed valve HV-CA1-1.

3. Causes a 30-second POT FLSH by Device BOT-DUMP.

\section{COMMANDS:}

CO BYPA OFF: Activates the interlock condition. Cannot be placed in this status unless PB-1 is not running.

C1 BYPA ON: Inhibits the interlock condition. Cannot be placed in this status unless PB-1 is not running.

AUTO/MAN: $\quad$ AUTO locks out all commands. The device should always be in MANUAL.

INTERLOCKS: This device has no interlocks.

OVERRIDE: $\quad$ Not used and has no effect on the device.

STATUSES:

SO BYPA OFF: $\quad$ PB-1 is off and interlocks to other devices are active.

S1 BYPA ON: $\quad$ PB-1 is off and interlocks to other devices are inhibited.

S2 PB1 ON: $\quad$ PB-1 is on and interlocks to other devices are inhibited.

S3 TIME BYP: $\quad$ PB-1 is off and timer KY-PB1-1 has not timed out. Interlocks to other devices are inhibited.

FAULT: Not used on this device. 


\section{HNF-3569 REV 0}

\section{TEST DATA SHEET}

DEVICE: PB1-BYPAS

OUTPUTS

DESTN

VALUE $\quad$ DESCRIPTION

\$G2 "1" Bypass Permissive to other devices

$M T$ Verify that command 0 activates the interlock condition with the motor off.

$M T$ Verify that command 1 turns on the bypass.

TESTED BY 2Màteat DATE_ $12 / 19 / 98$ 


\section{MASTER DEVICE OXPB1PUMP}

DEV(S): PB-1

DRAWING: $H-2-99949$ SHT 9

DESCRIPTION: Controls the operation of PB-1 and associated interlocks. This device has both current and contact confirm.

COMMANDS:

CO STOP:

C1 START:

C2 SD-RESET:

C3 JOG:

AUTO/MAN:

INTERLOCKS:

OVERRIDE:

STATUSES: SO CF-OFF:

S1 CF-ON:

S2 SD-RESET: Temporary status during resetting of the SHUTDOWN status.

S3 CF-JOGNG: Jogging as confirmed by the motor contactor.

S4 SHUTDOWN: The motor has stopped as confirmed by the contactor or motor current without being commanded to stop. This could be due to an interlock (as indicated by the INTERLOK status) or due to some abnormal condition not monitored by the device. If no interlock is present after SHUTDOWN, attempting to restart the pump may result in a FAULT condition.

S5 INTERLOK: Indicates an interlock condition is present.

S6 STOPPING: The motor was commanded to stop but the motor confirms are still present.

S7 STARTING: The motor was commanded to start but the confirms have not been received yet.

FAULT: The device will fault when it does not stari, jog, or stop within the allowable time period after the associated command is issued. The FAULT condition can be cleared by going to OVERRIDE (Override Key). 
HNF-3569 REV 0

\section{MASTER DEVICE OXPBIWFIL}

DEV(S): PBIWFINLK

DRAWING: $\mathrm{H}-2-99949$ SHT 9

DESCRIPTION: This device allows the weight factor interlocks for PB-1 to be bypassed provided LI-CA1-3 is not low.

\section{COMMANDS:}

CONOBYPASS: Places the device in NOBYPASS mode (interlocks not bypassed).

C1 BYPASS: $\quad$ Places the device in BYPASS mode (bypasses interlocks).

AUTO/MAN: $\quad$ AUTO locks out all commands. The device should always be in MANUAL.

INTERLOCKS: This device has two interlocks (LI-CA1-1 and 2). Both interlocks must be present to shutdown PB-1. The interlocks can be bypassed provided LI-CA1-3 is not low. When LI-CA1-3 is low, the device is commanded to the NOBYPASS status.

OVERRIDE: OVERRIDE (Override Key) has no effect on this master device.

STATUSES:

SO NOBYPASS: Interlocks are not bypassed.

S1 BYPASS: Interlocks are bypassed.

S3 LI-CA1-3: $\quad$ LI-CA1-3 is low and interlocks are not bypassed.

S5 INTERLOK: An interlock is present.

FAULT: Not used on this device. 


\section{HNF-3569 REV 0}

\section{TEST DATA SHEET}

DEVICE: PB-1

INTERLOCKS: PB-1 Stops and will not start on interlock.

\begin{tabular}{|c|c|c|}
\hline EPN & VALUE & DESCRIPTION \\
\hline$\overline{\mathrm{Pl}-\mathrm{CA} 1-9}$ & $\overline{35}$ & Seal Water pressure Lo \\
\hline $\mathrm{FI}-\mathrm{CA} 1-1$ & 0.3 & Seal Water flow Lo \\
\hline II-PB1-1 & 260 & Motor Current Hi-Hi (Delayed $3 \mathrm{sec}$ ) \\
\hline$\$ G 8$ & "0" & WF interlocks from PB1WFINLK \\
\hline
\end{tabular}

\section{CONFIRMS}

EPN

II-PB1-1 20

YS-PB1-1 "1"

DESCRIPTION

Motor Current Confirm

Motor Contact Confirm

\section{OUTPUTS}

DESTN VALUE DESCRIPTION
?OUT1
NO
Motor Start(1)/Stop $(0)$

$m \vee$ Verify fault and override. Exception

$\underline{M}$ Verify that command 3 jogs the motor.

$M T$ Verify that command 1 turns on the motor.

$M J$ Verify that command 0 turns off the motor.

$M T$ Verify that the interlock stops motor and prevents starting of motor.

$M I$ Verify that command 2 resets the shutdown of the motor following interlock.

$M T$ Verify that the SHUTDOWN status is alarmed with a non-critical (yellow) alarm.

TESTED BY M Seat DATE 12/19/98 
DEVICE: PB1WFINLK

\section{INTERLOCKS}

EPN

\section{DESCRIPTION}

LI-CA1-2 33.83

Evaporator Level \#1 Lo-Lo

Evaporator Level \#2 Lo-Lo

OTHER

$\frac{\text { EPN }}{\text { LI-CA1-3 }} \quad \frac{\text { VALUE }}{370} \quad \frac{\text { DESCRIPTION }}{\text { Level \#3 Lo }}$

OUTPUTS

$\frac{\text { DESTN }}{\$ G 8} \quad \frac{\text { VALUE }}{0 / 1} \quad \frac{\text { DESCRIPTION }}{\text { Passes Interlock Condition to PB-1 }}$

MT Verify that the interlocks are passed to PB-1 when not bypassed.

$M T$ Verify that command 0 turns off the bypass condition.

MT Verify that command 1 turns on the bypass condition.

TESTED BY M Seato DATE $12 / 19 / 98$ 


\section{MASTER DEVICE OXPB2PUMP}

DEV(S): $\quad$ PB-2

DRAWING: $\mathrm{H}-2-99949 \mathrm{SHT} 10$

DESCRIPTION: Controls the operation of PB-2 and associated interlocks. This device has both current and contact confirm.

COMMANDS:

CO STOP:

C1 START: $\quad$ Starts PB-2 provided there is no interlock.

C2 SD-RESET: Resets the SHUTDOWN status and causes the STOP command to follow. If this status is alarmed, it will clear the alarm.

C3 JOG: $\quad$ Jogs PB-2 for 5 seconds provided no interlock is present.

AUTO/MAN: Auto locks out all commands. Device should always be in Manual.

INTERLOCKS: PB-2 has seven interlocks connected directly to Device PB-2 with additional interlocks passed from Devices PB2SLFILK and PB2WFINLK. These interlocks can be bypassed (see descriptions for PB2WFINLK and PB2SLFILK). PB-2 also has hardwired interlocks.

OVERRIDE: OVERRIDE (Override Key) causes the confirms to be ignored and will therefore clear the FAULT condition if it is present.

STATUSES:

SO CF-OFF:

S1 CF-ON:

S2 SD-RESET: Temporary status during resetting of the SHUTDOWN status.

S3 CF-JOGNG: Jogging as confirmed by the motor contactor.

S4 SHUTDOWN: The motor has stopped as confirmed by the contactor or motor current without being commanded to stop. This could be due to an interlock (as indicated by the INTERLOK status) or due to some abnormal condition not monitored by the device. If no interlock is present after SHUTDOWN, attempting to restart the pump may result in a FAULT condition.

S5 INTERLOK: Indicates an interlock condition is present.

S6 STOPPING: The motor has been commanded to stop but the contact and motor current confirm are still present.

S7 STARTING: The motor has been commanded to start but the contact and current confirms have not been received yet.

FAULT: The device will fault when it does not start, jog, or stop within the allowable time period after the associated command is issued. The FAULT condition can be cleared by going to OVERRIDE (Override Key). 


\section{MASTER DEVICE OXPB2SFIL}

\section{DEV(S): PB2SLFILK}

DRAWING: $\mathrm{H}-2-99949 \mathrm{SHT} 10$

DESCRIPTION: This device allows the slurry flushing interlock for PB-2 to be bypassed.

\section{COMMANDS:}

CO NOBYPASS: Places the device in NOBYPASS mode (interlocks not bypassed).

C1 BYPASS: $\quad$ Places the device in BYPASS mode (bypasses interlocks).

AUTO/MAN: $\quad$ AUTO locks out all commands. The device should always be in MANUAL.

INTERLOCKS: This device has one interlock that is activated whenever an evaporator flush or a farm flush is active (see Device HV-CA1-2).

OVERRIDE: OVERRIDE (Override Key) has no effect on this device.

STATUSES:

SO NOBYPASS: Interlocks are not bypassed.

S1 BYPASS: Interlocks are bypassed.

S5 INTERLOK: An interlock is present.

FAULT: Not used on this device. 


\section{TEST DATA SHEET}

DEVICE: PB-2

INTERLOCKS: PB-2 Stops and will not start on interlock.

\begin{tabular}{|c|c|c|}
\hline EPN & VALUE & DESCRIPTION \\
\hline$\overline{\mathrm{PI}-\mathrm{C} A 1-10}$ & 70 & Seal Water pressure Lo \\
\hline $\mathrm{Fl}-\mathrm{CA} 1-2$ & 0.95 & Seal Water flow Lo \\
\hline PI-CA1-8 & 170 & Slurry Outlet Pressure Hi \\
\hline PSH-CA1-3 & "0" & Slurry Outlet Pressure $\mathrm{Hi}$ \\
\hline TSH-PB2-1 & "0" & Pump Temp Hi \\
\hline YS-PB2-IL & "0" & Hardwired Interlocks Active \\
\hline PSH-PB2-1 & "0" & Rupture Disk Broken \\
\hline$\$$ G9 & "0" & WF interlocks from PB2WFI \\
\hline$\$ G 11$ & "0" & Interlocks from PB2SLFILK \\
\hline
\end{tabular}

\section{CONFIRMS}

\begin{tabular}{|c|c|c|}
\hline EPN & VALUE & DESCRIPTION \\
\hline YS-PB2-1 & "1" & Motor Contact Confirm \\
\hline
\end{tabular}

\section{OUTPUTS}

$\frac{\text { DESTN }}{\text { ?OUT1 }} \quad \frac{\text { VALUE }}{\text { NO }} \quad \frac{\text { DESCRIPTION }}{\text { Motor Start(1)/Stop }(0)}$

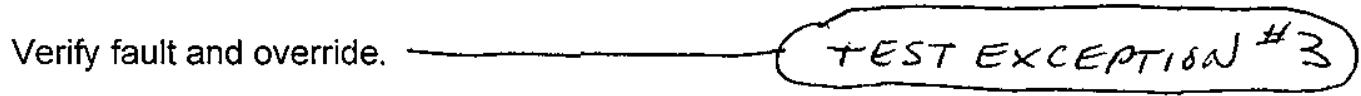

MT Verify that command 3 jogs the motor.

MT Verify that command 1 turns on the motor.

MT Verify that command 0 turns off the motor.

$M T$ Verify that the interlock stops motor and prevents starting of motor.

$M T$ Verify that command 2 resets the shutdown of the motor following interlock.

TESTED BY MV DATE $12 / 19 / 98$ 
HNF-3569 REV 0

TEST DATA SHEET

DEVICE: PB2SLFILK

INTERLOCKS

$\frac{\text { SOURCE }}{\text { \$G4 }} \quad \frac{\text { VALUE }}{\text { "0" }} \quad \frac{\text { DESCRIPTION }}{\text { Slurry Flush Active }}$

OUTPUTS

DESTN VALUE DESCRIPTION

\$G11 $\quad \frac{\text { OI }}{\text { Passes interlock Condition to PB-2 }}$

$M T$ Verify that the interlocks are passed to PB-2 when not bypassed.

$M I$ Verify that command 0 turns off the bypass condition.

$M T$ Verify that command 1 turns on the bypass condition.

tested $M$ Sect Date $12 / 19 / 98$

81 


\section{HNF-3569 REV 0 \\ MASTER DEVICE OXPB2WFIL}

DEV(S): PB2WFINLK

DRAWING: $\mathrm{H}-2-99949$ SHT 10

DESCRIPTION: This device allows the weight factor interlocks for PB-2 to be bypassed.

COMMANDS:

CO NOBYPASS: Places the device in NOBYPASS mode (interlocks not bypassed).

C1 BYPASS: $\quad$ Places the device in BYPASS mode (bypasses interlocks).

AUTO/MAN: $\quad$ AUTO locks out all commands. The device should always be in MANUAL.

INTERLOCKS: This device has two interlocks (LI-CA1-1 and 2). Both interlocks must be present to shutdown PB-2.

OVERRIDE: $\quad$ OVERRIDE (Override Key) has no effect on this device.

STATUSES:

SO NOBYPASS: Interlocks are not bypassed.

S1 BYPASS: Interlocks are bypassed.

S5 INTERLOK: An interlock is present.

FAULT: Not used on this device. 
HNF-3569 REV 0

TEST DATA SHEET

DEVICE: PB2WFINLK

INTERLOCKS

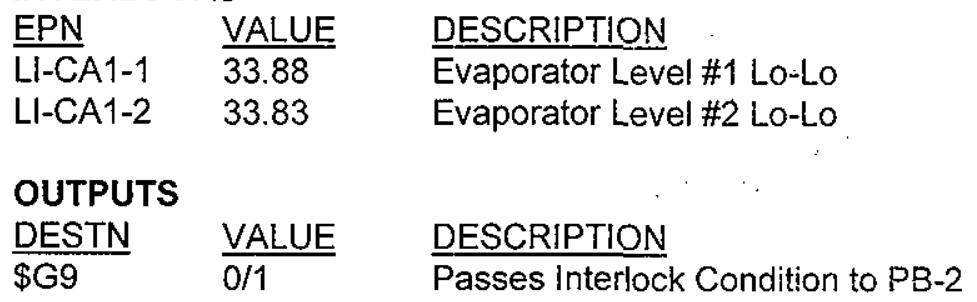

$M T$ Verify that the interlocks are passed to PB-2. when not bypassed.

$M I$ Verify that command 0 turns off the bypass condition.

MT Verify that command 1 turns on the bypass condition.

TESTED BY M Sector DATE $12 / 19 / 98$

83 


\section{MASTER DEVICE OXRC1DPIG}

DEV(S): $\quad$ RC1-PIG

DRAWING: $\quad H-2-99949$ SHT 19

DESCRIPTION: This master device controls the sample flow through the radiation monitoring pig for the RC1 sampling system. Timer KY-RC1-1 causes the pig sample stream to be periodically diverted and drained. If NO VENT is selected, the funnel valve is not opened during the divert/drain period (4 min 15 sec). If AUTOVENT is selected, the funnel valve will be opened during this time. Whenever PIG FLSH is selected, the device immediately goes to the Divert, Vent, and Drain valve positions and remains there until NO VENT or AUTOVENT is again selected. On occurrence of a radiation interlock, the valves revert to their normal position regardless of which command is selected. The radiation interlock can be bypassed using HS-RC1-6.

COMMANDS:

CO NO VENT: Causes the funnel valve to remain closed during diversion.

C1 AUTOVENT: Causes the funnel valve to open during diversion.

C2 PIG FLSH: Causes the valves to Divert, Vent, and Drain (no interlock).

AUTO/MAN: $\quad$ AUTO locks out all commands. The device should always be in MANUAL.

INTERLOCKS: Two radiation interlocks prohibit sample diversion. These interlocks are also hardwired.

OVERRIDE: Not used.

STATUSES:

SO NO VENT: Indicates the NO VENT command is selected.

S1 AUTOVENT: Indicates the AUTOVENT command is selected.

S2 PIG FLSH: Indicates that the PIG FLSH command is selected and the valves are in the Divert, Vent, and Drain position (unless interlocked).

S3 DI/DRAIN: $\quad$ The valves are placed in the Divert and Drain position, but the funnel valve remains closed (no confirms).

S4 DI/NN/DR: $\quad$ The valves are placed in the Divert, Vent, and Drain position.

S5 INTERLOK: Indicates the presence of an interlock.

S6 LOW FLOW: Indicates the existence of low flow to the sample pig. The low flow is inhibited during the timed diversion and for $75 \mathrm{sec}$ after return to normal and for 5.5 min during pig. flush. The low flow alarm is sent to Device CASSOAL2B for output to CASS.

S7 BYPASS Interlocks are bypassed.

FAULT: Not used. 


\section{HNF-3569 REV 0}

\section{TEST DATA SHEET}

DEVICE: RC1-PIG

INTERLOCKS: When an interlock is present; RC.1-PIG can not be diverted unless the hardwired bypass switch (HS-RC1-6) is in the bypass position.
EPN VALUE
DESCRIPTION
RI-RC1-1 80
Steam Condensate Sampler Rad Hi
RSH-RC1-1 "0"
Steam Condensate Sampler Rad Hi

\section{OTHER}

EPN

YS-RC1-6

VALUE
"1"
"0"

DESCRIPTION

FSL-RC1-1 "O"

Bypass switch in Bypass Position

Monitor Low Flow Indication

\section{OUTPUTS}

DESTN

VALUE

NO

?OUTDV

NO

?OUTF

NO

\$G18

"0"

DESCRIPTION
Output to Divert Valve HV-RC1-1
Output to Drain Valve HV-RC1-2.
Output to Funnel Valve. HV-RC1-4
Low Flow to CASSOAL2B

MT Verify command 0 puts the device in NO VENT.

MTVerify command 1 puts the device in AUTOVENT.

$m$ T Verify command 2 puts the device in PIG FLSH.

$M T$ Verify that a low flow non-critical (yellow) alarm is generated when the device is in PIG FLSH for longer than 5.5 minutes and the flow is low. START 13:29:00

MY Verify that when the device is not in PIG FLSH' or diverted by Timer KY-RC1-1, a low flow generates the alarm immediately.

DhT Verify that when RC1-SAMP is on, Timer KY-RC1-1 causes periodic flushing of the sample pig as determined by the timer set point.

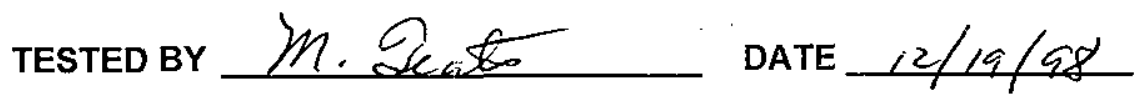




\section{MASTER DEVICE OXRC1SAMP}

DEV(S): RC1-SAMP

DRAWING: $\mathrm{H}-2-99949$ SHT 19

DESCRIPTION: Controls the operation of Pump.P-RC1-1 and Sampler RC1. When the sample pump is on, a signal is sent to the analog database to meter flow for proportional sampling. A signal is returned from the analog database each time a set number of gallons has been metered. This causes RC1-SAMP to pulse the sampler.

COMMANDS:

CO STOP:

Stops the pump and sends a signal to the analog database to stop metering flow for proportional sampling. Also stops Timer KY-RC1-1.

C1 START: $\quad$ Starts the pump provided there is no interlock. Starts Timer KY-RC1-1. Also sends a signal to the analog database to begin metering flow for proportional sampling.

C2 SD-RESET: Resets the SHUTDOWN status and causes the STOP command to follow. If this status is alarmed, it will clear the alarm.

C3 P-RC1-1: $\quad$ Starts the pump P-RC1-1 and timer KY-RC1-1, but prevents sampling.

AUTO/MAN: $\quad$ Auto locks out all commands. Device should always be in Manual.

INTERLOCKS: One interlock (TK-C-103 level low) will turn off the pump and the RC1 sampling system.

OVERRIDE: $\quad$ OVERRIDE (Override Key) causes the confirms to be ignored and will therefore clear the FAULT condition if it is present.

STATUSES:

SO CF-OFF:

Not running as confirmed by the motor contactor.

S1 CF-ON: $\quad$ Running as confirmed by the motor contactor.

S2 SD-RESET: Temporary status during resetting of the SHUTDOWN status.

S3 P-RC1-1: $\quad$ KY-RC1-1 running, pump P-RC1-1 running, but sampler not being pulsed.

S4 SHUTDOWN: The motor has stopped as confirmed by the contactor without being commanded to stop. This could be due to an interlock (as indicated by the INTERLOK status) or due to some abnormal condition not monitored by the device. If no interlock is present after SHUTDOWN, attempting to restart the pump may result in a FAULT condition.

S5 INTERLOK: Indicates an interlock condition is present.

S6 STOPPING: The motor was commanded to stop but the contact confirm is still present.

S7 STARTING: The motor was commanded to start but contact confirm has not been received yet.

FAULT: The device will fault when it does not start or stop within the allowable time period after the associated command is issued. The FAULT condition can be cleared by going to OVERRIDE (Override Key). 


\section{TEST DATA SHEET}

DEVICE: RC1-SAMP

INTERLOCKS: P-RC1-1 Stops and will not start on interlock.

EPN

VALUE DESCRIPTION

LSL-RC1-1 "0" TK-C-103 Level Lo

\section{CONFIRMS}

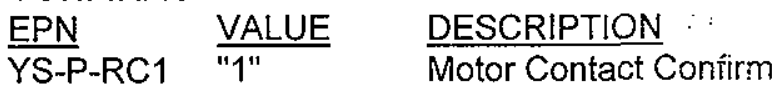

\section{OTHER}

SOURCE

$\$ T 21$

$\frac{\text { VALUE }}{" 1 "}$

DESCRIPTION

Signal to pulse Steam Condensate Sampler

\section{OUTPUTS}

DESTN

?OUT1

?OUT2

\$G15

VALUE
NO
NO
"1"

DESCRIPTION

Motor Start(1)/Stop(0)

Output to RC1 Sampler.

Permissive to start $K Y-R C 1-1$

$M T$ Verify that command 1 starts the motor.

MT Verify that command 0 stops the motor.

MT Verify that command 3 starts the motor.

$m T$ verify that the interlock stops motor and prevents starting of motor.

$m+V e r i f y$ that command 2 resets the shutdcwn of the motor following interlock.

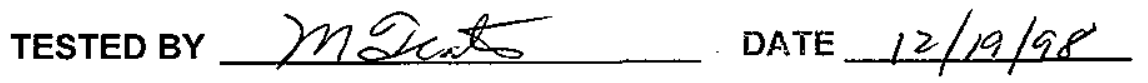




\section{MASTER DEVICE OXRC2DPIG}

\section{DEV(S): $\quad$ RC2-PIG}

DRAWING: $H-2-99949$ SHT 20

DESCRIPTION: This master device controls the sample flow through the radiation monitoring pig for the $\mathrm{RC} 2$ sampling system. Timer $\mathrm{KY}-\mathrm{RC} 2-1$ causes the pig sample stream to be diverted and drained on a periodic basis. If NO VENT is selected, the funnel valve is not opened during the divert/drain period (4 min $15 \mathrm{sec}$ ). If AUTOVENT is selected, the funnel valve will be opened during this time. Whenever PIG FLSH is selected, the device immediately goes to the Divert, Vent, and Drain valve positions and remains there until NO VENT or AUTOVENT is again selected. On occurrence of a radiation interlock, the valves revert to their normal position regardless of which command is selected. The radiation interlock can be bypassed using HS-RC2-6.

COMMANDS:

CO NO VENT: $\quad$ Causes the funnel valve to remain closed during diversion.

C1 AUTOVENT: Causes the funnel valve to open during diversion.

C2 PIG FLSH: Causes the valves to Divert, Vent, and Drain (no interlock).

AUTO/MAN: $\quad$ AUTO locks out all commands. The device should always be in MANUAL.

INTERLOCKS: Two radiation interlocks prohibit sample diversion. These interlocks are also hardwired.

OVERRIDE: $\quad$ Not used.

\section{STATUSES:}

SO NO VENT:

S1 AUTOVENT: Indicates the AUTOVENT command is selected.

S2 PIG FLSH: Indicates that the PIG FLSH command is selected and the valves are in the Divert, Vent, and Drain position (unless interlocked)

S3 DI/DRAIN: $\quad$ The valves are placed in the Divert and Drain position, but the funnel valve remains closed (no confirms).

S4 DINN/DR: $\quad$ The valves are placed in the Divert, Vent, and Drain position (no confirms).

S5 INTERLOK: Indicates the presence of an interlock.

S6 LOW FLOW: Indicates the existence of low flow to the sample pig. The low flow is inhibited during the timed diversion and for $75 \mathrm{sec}$ after return to normal and for $5.5 \mathrm{~min}$ during pig flush.

S7 BYPASS Interlocks are bypassed. 


\section{DEVICE: RC2-PIG}

INTERLOCKS: When an interlock is present, RC2-PIG can not be diverted unless the hardwired bypass switch (HS-RC2-6) is in the bypass position.

$\begin{array}{lll}\text { EPN } & \text { VALUE } & \text { DESCRIPTION } \\ \text { RI-RC2-1 } & 7.5 & \text { Used Raw Water Sampler Rad Hi } \\ \text { RSH-RC2-1 } & \text { "0" } & \text { Used Raw Water Sampler Rad Hi }\end{array}$

OTHER

EPN VALUE DESCRIPTION

YS-RC2-6 "1" $\quad$ Bypass switch in Bypass Position

FSL-RC2-1 "0" Monitor Low Flow Indication

OUTPUTS

DESTN VALUE DESCRIPTION

?OUTDV NO Output to Divert Valve HV-RC2-1

?OUTDR NO Output to Drain Valve HV-RC2-2

?OUTF NO Output to Funnel Valve HV-RC2-4

MT Verify command 0 puts the device in NO VENT.

$M \mathbb{T}$ Verify command 1 puts the device in AUTOVENT.

MFF Verify command 2 puts the device in PIG FLSH.

in Verify that a low flow non-critical (yellow) alarm is generated when the device is in PIG FLSH for longer than 5.5 minutes and the flow is low. START $11: 33: 55$

MI Verify that when the device is not in PIG FLSH or diverted by Timer KY-RC2-1, a low flow generates the alarm immediately.

MI Verify that when RC2-SAMP is on, Timer KY-RC2-1 causes periodic flushing of the sample pig as determined by the timer set point.

TESTED BY M Date $12 / 19 / 98$ 


\section{MASTER DEVICE OXRC2SAMP}

DEV(S): RC2-SAMP

DRAWING: $\mathrm{H}-2-99949 \mathrm{SHT} 20$

DESCRIPTION: Controls the operation of Valve HV-RC2-5. and Sampler RC2. When the valve is opened, a signal is sent to the analog database to meter flow for proportional sampling. A signal is returned from the analog database each time a set number of gallons has been metered. This causes RC2-SAMP to pulse the sampler.

\section{COMMANDS:}

CO STOP:

Closes (no confirm) valve HV-RC2-5 and sends a signal to the analog database to stop metering flow for proportional sampling. Also stops Timer KY-RC2-1.

C1 START: Opens (no confirm) valve HV-RC2-5. Starts Timer KY-RC2-1. Also sends a signal to the analog database to begin metering flow for proportional sampling.

C2 HV-RC2-5: Starts KY-RC2-1 and opens HV-RC2-5, but prevents sampling.

AUTO/MAN: Auto locks out all commands. Device should always be in Manual.

INTERLOCKS: This device has no interlocks.

OVERRIDE: Not used.

STATUSES:

SO STOPPED: Sampler not running and valve HV-RC2-5 closed.

S1 RUNNING: Running and valve HV-RC2-5 open.

S2 HV-RC2-5: $\quad \mathrm{KY}-\mathrm{RC} 2-1$ running, $\mathrm{HV}-\mathrm{RC} 2-5$ open, but sampler not running.

S3 SAMPLE: Sampler is being pulsed.

S5 INTERLOK: Indicates an interlock condition, which cannot occur because the interlock inputs are all defined as $\$ G 1$ (constant logic "1"). This status is a vestige of old logic that had interlocks.

FAULT: Not used. 


\section{HNF-3569 REV 0}

\section{TEST DATA SHEET}

DEVICE: RC2-SAMP

OTHER

SOURCE

$\$ T 5$

VALUE

DESCRIPTION

OUTPUTS

DESTN

VALUE

?OUT1

NO

Signal to pulse URW Sampler

?OUT2

$\$ \mathrm{G} 16$

NO

"1"

DESCRIPTION

Output to Open HV-RC2-5

Output to pulse URW Sampler

Permissive to start Timer KY-RC2-1

MT Verify that command 1 starts the sampler.

MT Verify that command 0 stops the sampler.

MT Verify that command 2 starts $K Y-R C 2-1$, but does not start sampler.

TESTED BY M Seat

DATE $12 / 19 / 98$ 


\section{MASTER DEVICE OXRC3DPIG}

DEV(S): RC3-PIG

DRAWING: $\quad \mathrm{H}-2-99949$ SHT 21

DESCRIPTION: This device controls the sample flow through the radiation monitoring pigs for the RC3 sampling system. Timer KY-RC3-1 causes the pig sample stream to be diverted and drained on a periodic basis when the NO VENT command is selected. Whenever PIG FLSH is selected, the device immediately goes to the Divert and Drain valve positions and remains there until NO VENT is again selected. The funnel (vent) valve on this sample pig is not automatically controlled.

On occurrence of a radiation interlock, the valves revert to their normal position regardless of which status (NO VENT or PIG FLSH) is selected. The radiation interlock can be bypassed using HS-RC3-6.

\section{COMMANDS:}

CONO VENT: $\quad$ Causes the valves to Divert and Drain whenever the timer KY-RC3-1 activates.

C1 NO VENT: $\quad$ Same as C0.

C2 PIG FLSH: Causes the valves to Divert and Drain provided no interlock is present.

AUTO/MAN: $\quad$ AUTO locks out all commands. The device should always be in MANUAL.

INTERLOCKS: Two radiation interlocks prohibit sample diversion when the radiation is high. These interlocks are also hardwired.

OVERRIDE: $\quad$ Not used.

STATUSES:

SO NO VENT: Indicates the NO VENT command is selected.

S2 PIG FLSH: Indicates that the PIG FLSH command is selected and the valves are in the Divert and Drain position (unless interlocked).

S3 DI/DRAIN: $\quad$ The valves are placed in the Divert and Drain position.

S5 INTERLOK: Indicates the presence of an interlock.

S6 LOW FLOW: Indicates the existence of low flow to the sample pig. The low flow is inhibited during the timed diversion and for $75 \mathrm{sec}$ after return to normal and for $5.5 \mathrm{~min}$ during pig flush.

S7 BYPASS Interlocks are bypassed.

FAULT: Not used. 


\section{HNF-3569 REV 0}

\section{TEST DATA SHEET}

DEVICE: RC3-PIG

INTERLOCKS: When an interlock is present, RC3-PIG can not be diverted unless the hardwired bypass switch (HS-RC3-6) is in the bypass position.

EPN VALUE DESCRIPTION

RI-RC3-1 $45 \quad$ Process Condensate Sampler Rad Hi

RSH-RC3-1 "0" Process Condensate Sampler Rad Hi

\section{OTHER}

EPN VALUE DESCRIPTION

YS-RC3-6 "1" Bypass switch in Bypass Position

FSL-RC3-1 "0" Monitor Low Flow Indication

OUTPUTS

DESTN VALUE DESCRIPTION

?OUTDV NO Output to Divert Valve HV-RC3-1

$m T$ Verify command 0 puts the device in NO VENT.

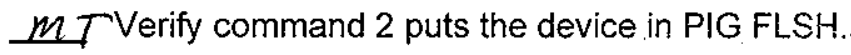

$m I$ Verify that a low flow non-critical (yellow) alarm is generated when the device is in PIG FLSH for longer than 5.5 minutes and the flow is low. START 13:40:05

$M T$ Verify that when the device is not in PIG FLSH or diverted by Timer KY-RC3-1, a low flow generates the alarm immediately.

$\underline{m} \mathcal{T}$ Verify that when RC3-SAMP is on, Timer KY-RC3-1 causes periodic flushing of the sample pig as determined by the timer set point. 


\section{MASTER DEVICE OXRC3SAMP}

$\operatorname{DEV}(\mathbf{S}): \quad$ RC3-SAMP

DRAWING: $\mathrm{H}-2-99949$ SHT 21

DESCRIPTION: Controls the operation of Sampler RC3. When the sampler is running, a signal is sent to the analog database to meter flow for proportional sampling. A signal is returned from the analog database each time a set number of gallons has been metered. This causes RC3-SAMP to pulse the sampler.

\section{COMMANDS:}

CO STOP: $\quad$ Stops the sampler and sends a signal to the analog database to stop metering flow for proportional sampling. Also stops Timer KY-RC3-1.

C1 START: $\quad$ Starts the sampler and sends a signal to the analog database to begin metering flow for proportional sampling. Also starts Timer KY-RC3-1.

AUTO/MAN: $\quad$ Auto locks out all commands. Device should always be in Manual.

INTERLOCKS: No interlocks.

OVERRIDE: $\quad$ Not used.

STATUSES:

SO STOPPED: Sampler not running.

S1 RUNNING: Sampler running.

S3 SAMPLE: $\quad$ Sampler is being pulsed.

FAULT: Not used. 
HNF-3569 REV 0

TEST DATA SHEET

DEVICE: RC3-SAMP

OTHER

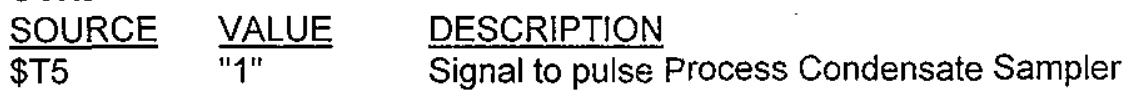

OUTPUTS

DESTN VALUE DESCRIPTION

?OUT

$\$$ G17

NO

Output to pulse PC Sampler

Permissive to start Timer KY-RC3-1

$M T$ Verify that command 1 starts the sampler.

$M \sigma$ Verify that command 0 stops the sampler.

TESTED BY $M$ Disease DATE $12 / 19 / 98$

MT Verify command 2 selects no sample.

$12 / 19 / 98$

95 
HNF-3569 REV 0

\section{MASTER DEVICE OXSELECDI}

DEV(S): SELECT-DI

DRAWING: $\mathrm{H}-2-99949$ SHT 39

DESCRIPTION: This device is used to select either the \#1 or \#2 Tubes for use in the density calculation.

COMMANDS:

CONO CMD: Has no effect on the device.

C1\#1 TUBES: $\quad$ Selects the \#1 Tubes.

C2 \#2 TUBES: $\quad$ Selects the \#2 Tubes.

AUTO/MAN: $\quad$ Auto locks out all commands. Device should always be in Manual.

INTERLOCKS: No interlocks.

OVERRIDE: $\quad$ Not used.

STATUSES:

SO NO CMD: $\quad$ Temporary status if NO CMD $(C O)$ is selected.

S1 Dl-CA1-1: $\quad$ \#1 Tubes are being used for the density calculation.

S2 DI-CA1-2: \#2 Tubes are being used for the density calculation.

FAULT: Not used. 


\section{MASTER DEVICE OXSELECTI}

DEV(S): SELECT-TI

DRAWING: $H-2-99949$ SHT 39

DESCRIPTION: This device is used to select one of two temperature elements (TI-EA1-7 or TI-CA1-7). COMMANDS:

C0 TI-EA1-7: Selects TI-EA1-7.

C1 TI-CA1-7: $\quad$ Selects TI-CA1-7.

AUTO/MAN: Auto locks out all commandis. Device should always be in Manual.

INTERLOCKS: No interlocks.

OVERRIDE: Not used.

STATUSES:

SO TI-EA1-7: $\quad$ TI-EA1-7 is selected.

S1 TI-CA1-7: TI-CA1-7 is selected.

FAULT: Not used. 
HNF-3569 REV 0

\section{MASTER DEVICE OXSELECWF}

DEV(S): SELECT-WF

DRAWING: $\quad$ H-2-99949 SHT 39

DESCRIPTION: This device is used to select either the \#1 or \#2 WF for use in the level calculation.

COMMANDS:

CONO CMD: Has no effect on the device.

C1 LI-CA1-1: $\quad$ Selects WFI-CA1-1.

C2 LI-CA1-2: $\quad$ Selects WFI-CA1-2.

AUTOIMAN: $\quad$ Auto locks out all commands. Device should always be in Manual.

INTERLOCKS: No interlocks.

OVERRIDE: Not used.

STATUSES:

SO NO CMD: $\quad$ Temporary status if NO CMD (CO) is selected.

S1 LI-CA1-1: WFI-CA1-1 is being used in the level calculation.

S2 LI-CA1-2: WFI-CA1-2 is being used in the level calculation.

FAULT: Not used. 
HNF-3569 REV 0

TEST DATA SHEET

DEVICE: SELECTED!

MT Verify that command 0 has no effect.

MT Verify that command 1 selects \#1 tubes.

MF Verify that command 2 selects \#2 tubes.

DEVICE: SELECT-TI

MT F Verify that command 0 selects TI-EA $1-7$.

MT Verify that command 1 selects TI-CA 1-7.

DEVICE: SELECT-WF

MT Verify that command 0 has no effect.

$M T$ Verify that command 1 selects WFI-CA1-1.

$M T$ Verify that command 2 selects WFI-CA1-2.

TESTED BY Ma cato DATE $12 / 19 / 98$

99 


\section{MASTER DEVICE OXSLFLUSH}

$\operatorname{DEV}(\mathrm{S}): \quad H V-C A 1-2$

DRAWING: $\quad \mathrm{H}-2-99949$ SHT .14

DESCRIPTION: Controls the slurry flush system. Can be operated either manually or in automatic mode. Whenever flushing is active a signal is sent to Device HV-CA1-6 causing it to open. During flushing a signal is also sent to PB2-INLK2 which causes PB-2 to shutdown (except when PB2-INLK2 is in BYPASS).

COMMANDS:

CO BLOCK:

Put HV-CA1-2 in Position 2 (air on) and HV-CA1-2A in Position 2 (air off).

C1 SL OUT:

Put HV-CA1-2 in Position 1 (air ofi) and HV-CA1-2A in Position 1 (air on).

C2 EVAP FL:

Put HV-CA1-2 in Position 2 (air on) and HV-CA1-2A in Position 1 (air on).

C3 FARM FL:

Put HV-CA1-2 in Position 1 (air off) and HV-CA1-2A in Position 2 (air off). Send signal to Device HV-CA1-6 to open HV-CA1-6.

C4 LO-RESET: Resets LOCKOUT condition, then goes to BLOCK. See LOCKOUT status below.

AUTO: If the device is not in LOCKOUT status, the occurrence of low slurry flow (as determined by FSLCA1-4) will start Timer KY-CA1-2. If the slurry flow is restored it stops and resets the timer.

If Timer KY-CA1-2 times out it will initiate the automatic flush sequence. The automatic sequence consists of a 30 second EVAPORATOR FLUSH followed by a FARM FLUSH (Timer KY-CA1-2F). Upon completion of the FARM FLUSH, the valves are placed in the BLOCK position and the LOCKOUT status is set. In LOCKOUT the automatic flush is locked out until manually reset (LO-RESET).

MANUAL: The operator may select the BLOCK, SL OUT, EVAP FL, FARM FL, or LO-RESET commands.

INTERLOCKS: This device has no interlocks.

OVERRIDE: Not used and has no effect on the device.

STATUSES:

SO BLOCK: $\quad$ HV-CA1-2 is in Position 2 (air on) and HV-CA1-2A is in Position 2 (air off).

S1 SL OUT: $\quad$ HV-CA1-2 is in Position 1 (air off) and HV-CA1-2A is in Position 1 (air on).

S2 EVAP FL: $\quad$ HV-CA1-2 is in Position 2 (air on) and HV-CA1-2A is in Position 1 (air on).

S3 FARM FL: $\quad$ HV-CA1-2 is in Position 1 (air off) and HV-CA1-2A is in Position 2 (air off).

S4 LO-RESET: Temporary status when reset is commanded. Always followed by BLOCK status.

S5 LOCKOUT: $\quad$ Valves are in the BLOCK position and the auto flush sequence is inhibited.

FAULT: Not used on this device.

SPECIAL DESCRIPTION: If the auto flush sequence has been initiated, switching from AUTO to MANUAL will not stop the sequence unless the LO-RESET command is invoked. Upon completion of the auto sequence, the status will be LOCKOUT, which can be reset with the LO-RESET command. 
HNF-3569 REV 0

TEST DATA SHEET

DEVICE: HV-CA1-2

OTHER

$\frac{\text { EN }}{\text { FIC-CA1-4 }} \frac{\text { VALUE }}{42} \quad \frac{\text { DESCRIPTION }}{\text { Slurry Flow Lo }}$

OUTPUTS

DESTN VALUE DESCRIPTION

?OUT2 NO Air On (Pos 2). for HV-CA1-2

?OUT2A NO Air On (Pos 1) for HV-CA1-2A

$M T$ Verify that command 0 puts the valves in BLOCK.

$M Y$ Verify that command 1 puts the valves in SL OUT.

$m T$ Verify that command 2 puts the valves in EVAP FL.

$M T$ Verify that command 3 puts the valves in FARM FL.

$M T$ Verify the automatic flush sequence following interlock when in AUTO status.

$m$ Verify that command 4 resets the LOCKOUT condition.

START 13:54:50

tested by M Seato dATE 12/19/98

$$
\begin{array}{ll}
K Y-C A I-2 & S P=8 \\
K Y-C A 1-2 F & S P=7.5
\end{array}
$$

101 


\section{MASTER DEVICE OXSWAPUMP}

$\operatorname{DEV}(\mathrm{S}): \quad$ P-C-105 P-C-105A

DRAWING: $\mathrm{H}-2-99949$ SHTS 7 and 8

DESCRIPTION: Controls the operation of the two seal water pumps. Allows the designation of a Primary and Secondary pump. Only one pump need be operated if it can maintain pressure and flow.

COMMANDS:

CO STOP:

Stops the pump when in manual.:

C1 START: $\quad$ Starts the pump when in manual.

C2 SF-RESET: Resets the start-fail status and causes the STOP command to follow. If this status is alarmed, it will clear the alarm.

AUTO/MAN: When in AUTO a pump is designated as the Secondary (standby) pump to be started automatically in the event seal water flow and pressure can not be maintained with the other pump. When in MANUAL a pump is designated as the Primary pump and must be started manually. The Primary pump will provide a start signal to the Secondary pump (after two minutes) in the event seal water pressures and flows cannot be maintained. When in MANUAL, a pump will ignore any auto start signal from the other pump. Failure to establish the required minimum pressures and flows for a period of four minutes while a pump is running will also stop the pump regardless of the AUTO/MAN status.

INTERLOCKS: No interlocks.

OVERRIDE: $\quad$ OVERRIDE (Override Key) causes the confirms to be ignored and will therefore clear the FAULT condition if it is present.

STATUSES:

SO CF-OFF:

Not running as confirmed by the motor contactor.

S1 CF-ON: $\quad$ Running as confirmed by the motor contactor.

S2 SF-RESET: Temporary status during resetting of the STRTFAlL status.

S4 STRTFAIL: $\quad$ The motor failed to auto-start (commanded by the other pump device) because it was in MANUAL.

S6 STOPPING: The motor has been commanded to stop but the contactor off confirm has not been received yet.

S7 STARTING: The motor has been commanded to start but the contactor on confirm has not been received yet.

FAULT: The device will fault when it does not start or stop within five seconds after the command is issued. It will also fault if the contactor opens due to some external condition. The fault can be cleared by going to OVERRIDE. 


\section{TEST DATA SHEET}

DEVICE: P-C-105

OTHER

EPN

PI-CA1-9 40

DESCRIPTION

FI-CA1-1 0.42

Seal Water pressure Lo

Seal Water flow Lo

PI-CA1-10 75

FI-CA1-2 1.0

Seal Water pressure Lo

\$G6 "i"

Seal Water flow Lo

Start Signal from P-C-105A

CONFIRMS

EPN

YS-PC-105

$\frac{\text { VALUE }}{\text { "q" }}$

DESCRIPTION

Motor Contact Confirm

OUTPUTS

DESTN

?OUT1

VALUE

NO

"1"

DESCRIPTION

Motor Start(1)/Stop(0)

$\$$ G5

Start Signal to P-C-105A

m Verify proper operation of pump with commands:

$M \sigma$ Verify that P-C-105A automatically starts if seal water pressure or flow do not reach minimums within 2 minutes.

$12 \div 26 \div-45$

$10: 29: 20$ S7AQ:

MK Verify that upon loss of seal water pressure or flow, the pump stops four minutes later.

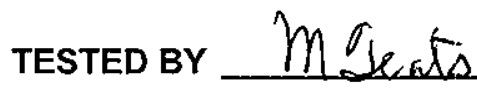

DATE $12 / 19 / 98$ 


\section{HNF-3569 REV 0}

\section{TEST DATA. SHEET}

DEVICE: P-C-105A

OTHER

EPN

PI-CA1-9 40

FI-CA1-1 0.42

PI-CA1-10 75

FI-CA1-2 1.0

$\$ \mathrm{G5}$ "1"

DESCRIPTION

Seal Water pressure Lo

Seal Water flow Lo

Seal Water pressure Lo

Seal Water flow Lo

Start Signal from P-C-105

\section{CONFIRMS}

EPN

VALUE

DESCRIPTION

Motor Contact Confirm

OUTPUTS

\begin{tabular}{|c|c|c|}
\hline DESTN & VALUE & DESCRIPTION \\
\hline $\begin{array}{l}\text { ?OUT1 } \\
\text { \$G6 }\end{array}$ & $\begin{array}{l}\text { NO } \\
" 1 "\end{array}$ & Motor Start(1)/Stop(0) \\
\hline
\end{tabular}

$M T$ Verify proper operation of pump with commands.

$M$ Verify that P-C-105 automatically starts if seal water pressure or flow do not reach minimums within 2 minutes.

$M T$ Verify that upon loss of seal water pressure or flow, the pump stops four minutes later.

TESTED BY M Deat DATE $12 / 19 / 98$ 


\section{MASTER DEVICE OXVCA1ILK}

$\operatorname{DEV}(\mathbf{S}): \quad$ VCA1-INLK

DRAWING: $\mathrm{H}-2-99949 \mathrm{SHT} 6$

DESCRIPTION: This device is used to bypass interlocks that are passed to device HV-CA1-1. It also monitors a hardware bypass switch and goes to the BYPASS state whenever the switch is in bypass. A timer (KY-CA1-1) limits the amount of time the interlocks can be bypassed. When the hardware switch is moved from bypass to normal, the device is placed in NOBYPASS status, however, it can be returned to BYPASS using the $\mathrm{C} 1 \mathrm{command}$.

\section{COMMANDS:}

CONOBYPASS: Puts the device into NOBYPASS status unless the hardware bypass switch is in the bypass position.

C1 BYPASS: $\quad$ Puts the device into BYPASS status.

AUTO/MAN: Auto locks out all commands. Device should always be in Manual.

INTERLOCKS: This device has ten interlocks.

OVERRIDE: OVERRIDE (Override Key) has no effect on this master device.

STATUSES:

SO NOBYPASS: Not in bypass.

S1 BYPASS: $\quad$ Bypass condition is on.

S5 INTERLOK: An interlock condition exists and is being passed to device HV-CA1-1 unless in BYPASS.

FAULT: Not used on this device. 


\section{HNF-3569 REV 0}

\section{TEST DATA SHEET}

DEVICE: VCA1-INLK

\section{INTERLOCKS}

\begin{tabular}{|c|c|c|}
\hline EPN & VALUE & DESCRIPTION \\
\hline LI-CA1-1 & 65.8 & Evaporator Level \#1 Hi \\
\hline LI-CA1-2 & 65.45 & Evaporator Level \#2 Hi \\
\hline RI-CA1-1 & 8000 & Process Condensate Line Rad $\mathrm{Hi}$ \\
\hline PDI-CA1-1 & 4.5 & Lower De-Entrainer DP Hi \\
\hline PDI-CA1-2 & 4.5 & Upper De-Entrainer DP Hi \\
\hline WFSH-CA11 & "0" & Evaporator WF \#1 Hi \\
\hline WFSH-CA12 & "0" & Evaporator WF \#2 Hi \\
\hline RSH-CA1-1 & "0" & Process Condensate Line $\mathrm{R}$ \\
\hline PDSH-CA1 & "0" & Lower De-Entrainer DP Hi \\
\hline
\end{tabular}

BYPASS

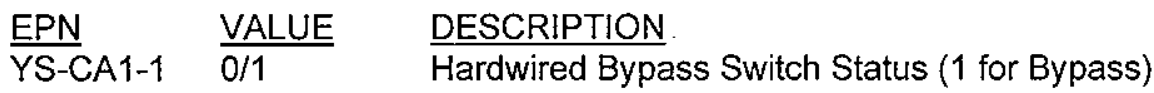

OUTPUTS

DESTN VALUE DESCRIPTION

\$G10 0/1 Passes Interlock Condition to HV-CA1-1

MT Verify that command 1 turns on the bypass condition.

MT Verify that command 0 turns off the bypass condition.

$M T$ Verify that the interlocks are passed to HV-CA1-1 when not bypassed.

$M T$ Verify that when hardwired bypass switch is placed in bypass, device goes to BYPASS status.

$M$ Verify that when hardwired bypass switch is placed in normal, device goes to NOBYPASS status.

TESTEd BY Matento DATE $12 / 19 / 98$ 


\section{HNF-3569 REV 0}

\section{MASTER DEVICE OXVSTATCO}

$\operatorname{DEV}(\mathbf{S}): \quad$ HV-CA1-7 HV-CA1-9

DRAWING: $\quad H-2-99949$ SHT 13

DESCRIPTION: This master device provides status information for a valve with two-position limit switch confirmation. No valve control is available from this device.

COMMANDS: None

AUTO/MAN: $\quad$ Will work in either AUTO or MANUAL.

INTERLOCKS: None

OVERRIDE: OVERRIDE (Override Key) has no effect on this master device.

STATUSES:

SO CF-CLOSD: Valve is closed as confirmed by limit switch.

S1 CF-OPEN: Valve is open as confirmed by limit switch.

S2 TRAVEL: Valve is between close and open positions.

FAULT: Not used on this device. 


\section{HNF-3569 REV 0}

\section{TEST DATA SHEET}

DEVICE: HV-CA1-7

CONFIRMS

EPN VALUE DESCRIPTION

ZS-CA1-7N "1" Confirm Open

ZS-CA1-7C "1" Confirm Closed

$M T$ Verify the correct statuses are indicated during operation such as flushing.

DEVICE: HV-CA1-9

\section{CONFIRMS}

$\frac{\text { EPN }}{Z S-C A 1-9 N} \frac{\text { VALUE }}{\text { "1" }} \quad \frac{\text { DESCRIPTION }}{\text { Confirm Open }}$

ZS-CA1-9C "1" Confirm Closed

$m T$ verify the correct statuses are indicated during operation such as flushing.

TESTED BY Materate DATE, 12/19/98 


\section{HNF-3569 REV 0}

\section{MASTER DEVICE OXVSTATRW}

DEV(S): HV-RW-1 HV-RW-2

DRAWING: $\quad H-2-99949$ SHT 13

DESCRIPTION: This master device provides status information for a valve with two-position limit switch confirmation. No valve control is available from this device.

COMMANDS: None

AUTO/MAN: $\quad$ Will work in either AUTO or MANUAL.

INTERLOCKS: None

OVERRIDE: OVERRIDE (Override Key) has no effect on this master device.

STATUSES:

SO CF-CLOSD: Valve is closed as confirmed by limit switch.

S1 CF-OPEN: Valve is open as confirmed by limit switch.

S2 OPEN 1+M: Valve has been open for more than 1 minute (yellow alarm).

FAULT: Not used on this device. 
DEVICE: HV-RW-1

\section{CONFIRMS}

EPN $\quad$ VALUE

ZS-RW-1N "1" Confirm Open

ZS-RW-1C "1" Confirm Closed

$M T$ Verify the correct statuses are indicated.

$M T$ Verify the alarm condition.

DEVICE: HV-RW-2

CONFIRMS

EPN

$\begin{array}{ll}\text { ZS-RW-2C "1" } & \text { Confirm Open } \\ \end{array}$

InI Verify the correct statuses are indicated.

II Verify the alarm condition.

TESTED BY M 2ect DATE $12 / 19 / 98$ 


\section{MASTER DEVICE OXVSTATNB}

DEV(S): HV-2-37 HV-2-34

DRAWING: $\quad$ H-2-99949 SHT 13

DESCRIPTION: This master device provides status information for a valve with two-position limit switch confirmation. No valve control is available from this device.

COMMANDS: None

AUTO/MAN: $\quad$ Will work in either AUTO or MANUAL.

INTERLOCKS: None

OVERRIDE: OVERRIDE (Override Key) has no effect on this master device.

STATUSES:

SO CF-NORM: Valve is in the normal position as confirmed by limit switch.

S1 CF-BKFL: $\quad$ Valve is in the backflush position as confirmed by limit switch.

S2 TRAVEL: $\quad$ Valve is between close and open positions.

FAULT: Not used on this device.

\section{TEST DATA SHEET}

DEVICE: HV-2-37, or HV-2-34

\section{CONFIRMS}

FOR DEVICE

$\mathrm{HV}-2-37$

HV-2-37

HV $-2-34$

$\mathrm{HV}-2-34$

$\begin{array}{ll}\text { EPN } & \text { VALUE } \\ \text { ZS-IDX1NM } & \text { "1" } \\ \text { ZS-IDX1B } " 1 " \\ \text { ZS-IDX3NM "1" } \\ \text { ZS-IDX3B "1" }\end{array}$

DESCRIPTION

Confirm Normal Position

Confirm Backflush Position

Confirm Normal Position

Confirm Backflush Position

$M \backslash$ Verify the correct statuses are indicated for one of the devices.

tested by M Seats

DATE $12 / 19 / 98$ 


\section{MASTER DEVICE OXVSTATSL}

DEV(S): HV-CA1-2S

DRAWING: $\quad H-2-99949$ SHT 13

DESCRIPTION: This master device provides status information for the slurry valves using the limit switches. No valve control is available from this device.

COMMANDS: None

AUTO/MAN: Will work in either AUTO or MANUAL.

INTERLOCKS: None

OVERRIDE: OVERRIDE (Override Key) has no effect on this master device.

STATUSES:

SO BLOCK: · HV-CA1-2 in Position 2 and HV-CA1-2A in Position 2.

S1 SL OUT: $\quad$ HV-CA1-2 in Position 1. and HV-CA1-2A in Position 1.

S2 FARM FL: $\quad$ HV-CA1-2 in Position 2 and HV-CA1-2A in Position 1.

S3 EVAP FL: $\quad$ HV-CA1-2 in Position 1 and HV-CA1-2A in Position 2.

FAULT: Not used on this device.

\section{TEST DATA SHEET}

DEVICE: HV-CA1-2S

CONFIRMS

\begin{tabular}{|c|c|c|}
\hline EPN & VALUE & DESCRIPTION \\
\hline ZS-CA1-21 & "1" & Confirm Position 1 \\
\hline ZS-CA1-22 & "1" & Confirm Position 2 \\
\hline ZS-CA12A1 & "1" & Confirm Position 1 \\
\hline ZS-CA12A2 & "1" & Confirm Position 2 \\
\hline
\end{tabular}

$M T$ Verify the correct statuses are indicated for one of the devices.

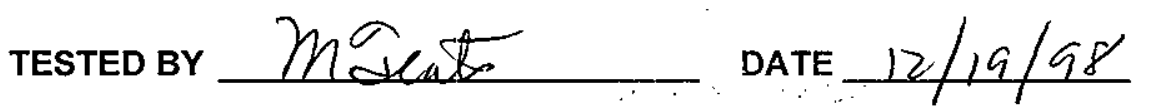




\subsection{TEST EXCEPTIONS}

Exceptions shall be documented using Figure 1, Exception to Software Acceptance Test (Appendix A). Exceptions to the test are dispositioned. Actions taken regarding disposition are noted on the exception sheet. Typical dispositions are:

1. Test approved with exception (rerun of the affected test procedure steps is unnecessary).

2. Test procedure step(s) affected to be repeated after the discrepancy has been corrected.

3. Entire Test Procedure to be repeated after the discrepancy has been corrected. 


\section{HNF-3569 REV 0}

\subsection{REFERENCES}

1. HNF-2695, 242A Distributed Control System Year 2000 Acceptance Test Procedure.

2. WHC-SD-534-ATR-001, Project B-534 Software Test Report.

3. WHC-SD-534-ATR-006, Project B-534 Acceptance Test Report.

4. WHC-SD-534-OTP-002, Operational Test Plan For 242-A Evaporator Upgrades and the Liquid Effluent Retention Facility. 


\subsection{INDEX TO DEVICES}

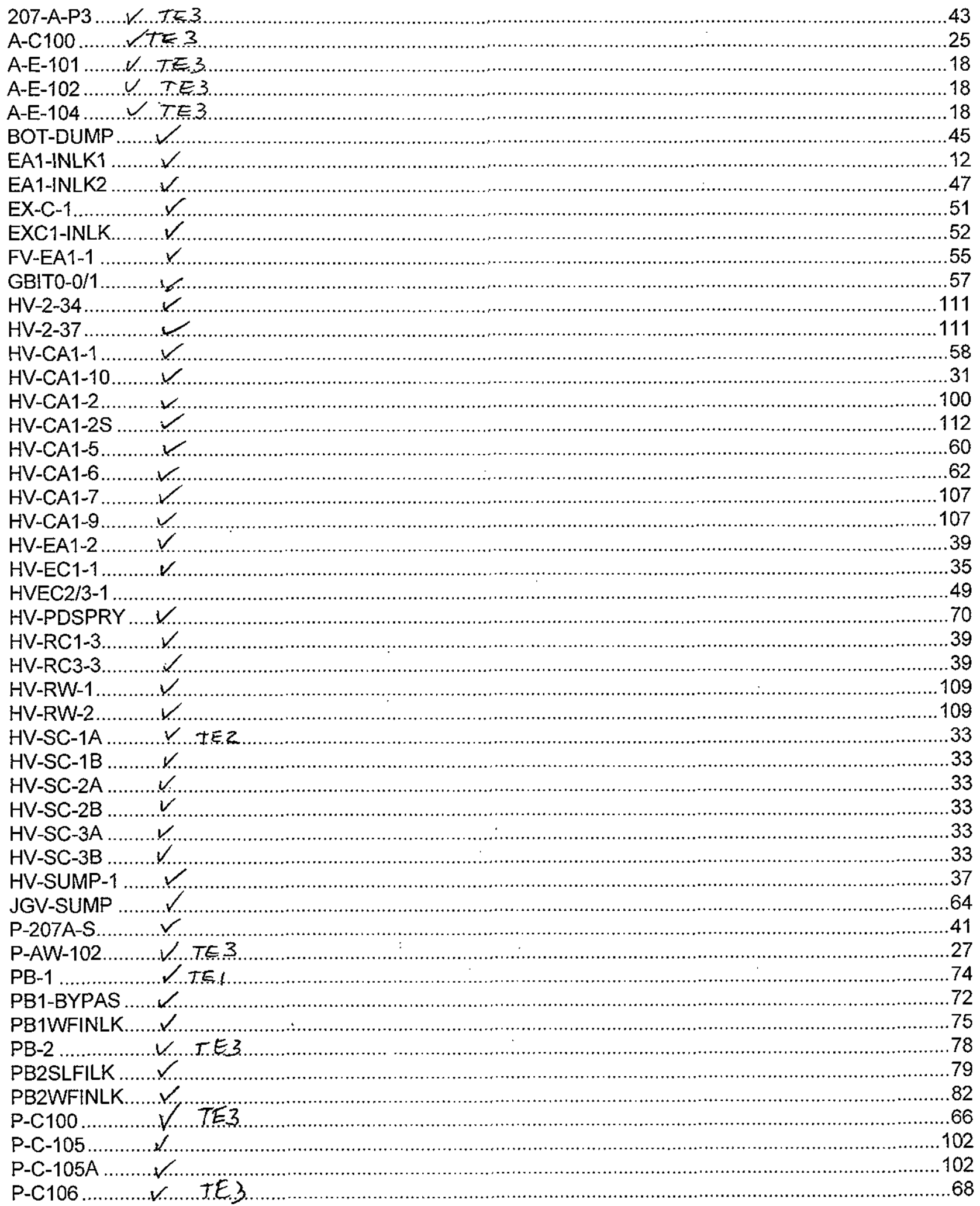




\section{HNF-3569 REV 0}

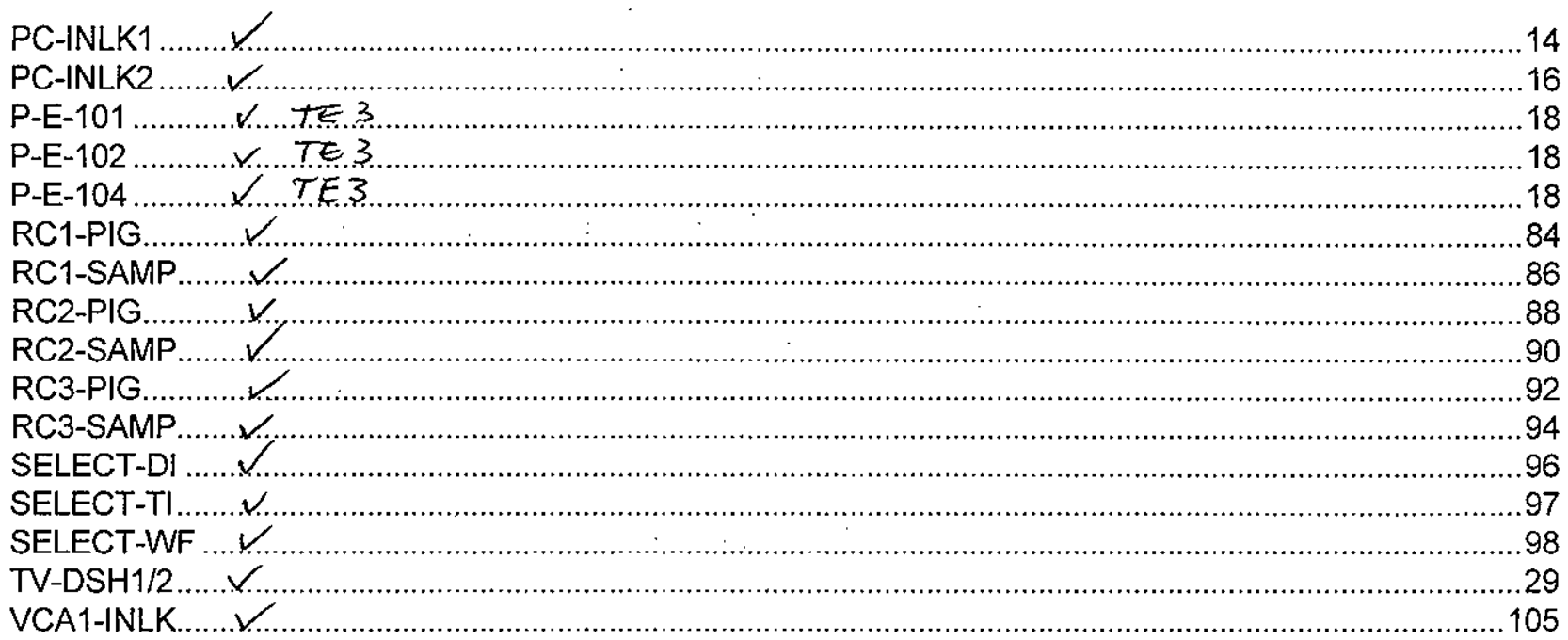


HNF-3569 REV 0

APPENDIX A 
FIGURE 1. TEST EXCEPTION LOG SHEET

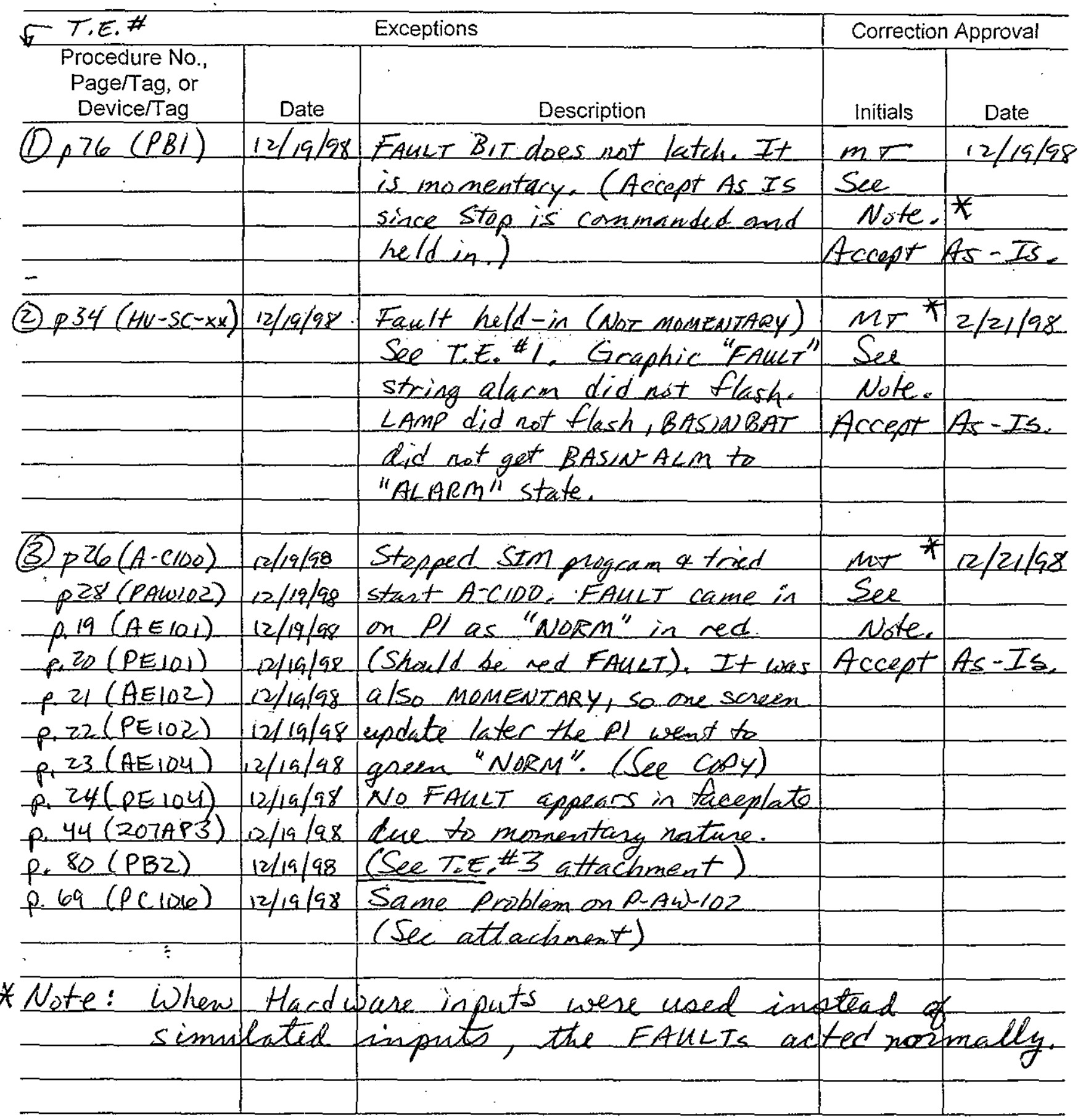

TEST APPROVED WITH EXCEPTIONS (RETEST UNNECESSARY):

engineering: Wh. Seats Date: $12 / 21 / 98$ 


\section{HNF-3569 REW Q}

TEST EXCEPTION 3 ATTACHMENT

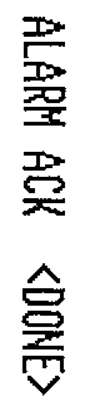

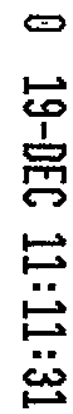

?

$\Leftrightarrow \quad H$

\begin{tabular}{ll}
7 & م \\
옹 & D \\
\hline &
\end{tabular}

点

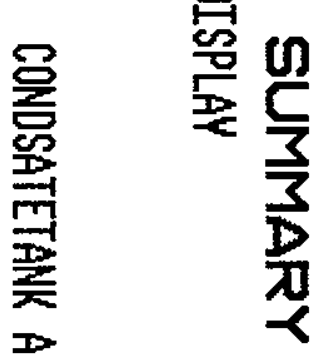

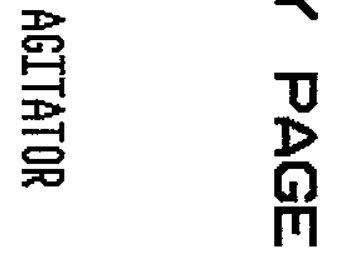

$\boldsymbol{Q}$

愛

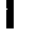

$\boldsymbol{Q}$ 


$$
\text { HNF-3569 REV } \Phi
$$

TEST EXCEPTION 3 ATIACHMENT

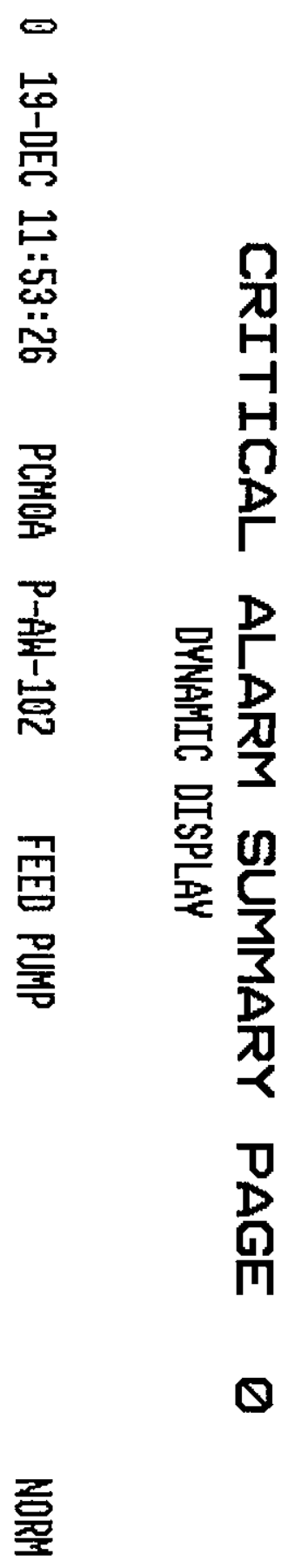




$$
\text { HNF- } 3569 \text { REVO }
$$

TEST EXCEPTION \#3 ATTACHMENT

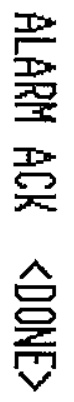

の

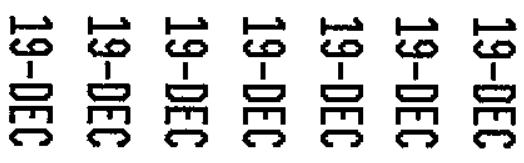

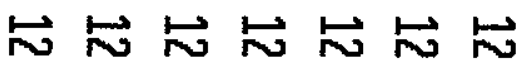

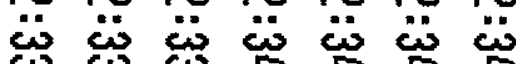

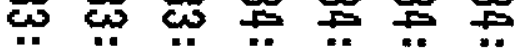

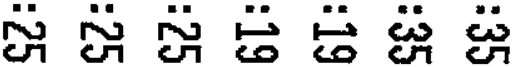

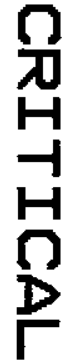

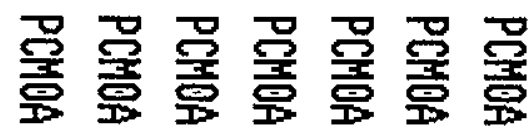

$\frac{2}{D}$

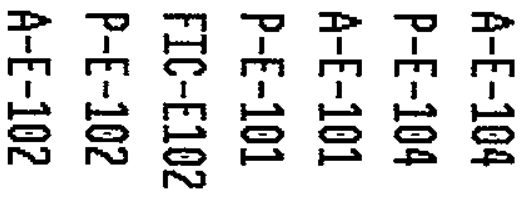

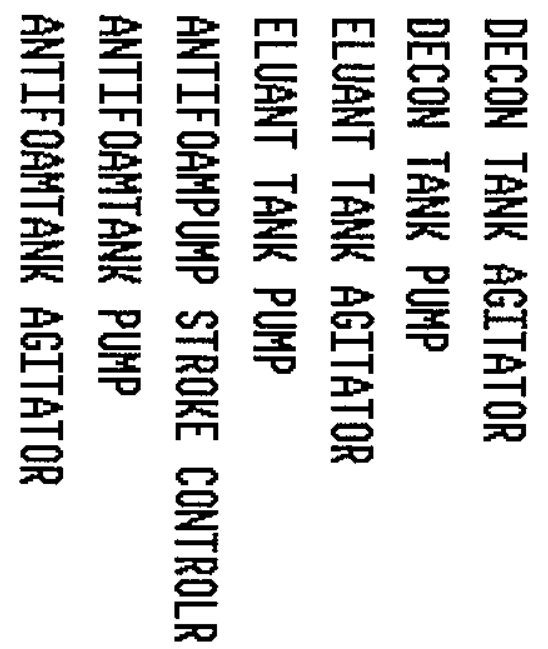

